\title{
EXIT VS. VOICE
}

Eleonora Broccardo

Oliver D. Hart

Luigi Zingales

Working Paper 27710

http://www.nber.org/papers/w27710

\author{
NATIONAL BUREAU OF ECONOMIC RESEARCH \\ 1050 Massachusetts Avenue \\ Cambridge, MA 02138
}

August 2020

We thank Patrick Bolton, Alex Edmans, Tore Ellingsen, Christian Leuz, Dirk Schoenmaker, Andrei Shleifer, Yossi Spiegel, Stefano Zamagni, and participants at the University of Chicago Finance lunch and the 2020 Stony Brook International Game Theory conference for very useful comments on a previous draft. Eleonora Broccardo gratefully acknowledges financial support from the Department of Economics and Management at the University of Trento. Luigi Zingales gratefully acknowledges financial support from the Stigler Center at the University of Chicago. The views expressed herein are those of the authors and do not necessarily reflect the views of the National Bureau of Economic Research.

NBER working papers are circulated for discussion and comment purposes. They have not been peer-reviewed or been subject to the review by the NBER Board of Directors that accompanies official NBER publications.

(C) 2020 by Eleonora Broccardo, Oliver D. Hart, and Luigi Zingales. All rights reserved. Short sections of text, not to exceed two paragraphs, may be quoted without explicit permission provided that full credit, including $\odot$ notice, is given to the source. 
Exit vs. Voice

Eleonora Broccardo, Oliver D. Hart, and Luigi Zingales

NBER Working Paper No. 27710

August 2020

JEL No. D02,D21,D23,D62,D64,H41,L21

\begin{abstract}
We study the relative effectiveness of exit (divestment and boycott) and voice (engagement) strategies in promoting socially desirable outcomes in companies. We show that in a competitive world exit is less effective than voice in pushing firms to act in a socially responsible manner. Furthermore, we demonstrate that individual incentives to join an exit strategy are not necessarily aligned with social incentives, whereas they are when well-diversified investors are allowed to express their voice. We discuss what social and legal considerations might sometimes make exit preferable to voice.

Eleonora Broccardo

University of Trento

Via Inama, 5 -

Trento 38122

Italy

eleonora.broccardo@unitn.it

Oliver D. Hart

Department of Economics

Littauer Center 220 Harvard

University Cambridge, MA

02138 and NBER

ohart@ harvard.edu

Luigi Zingales

Booth School of Business

The University of Chicago

5807 S. Woodlawn Avenue

Chicago, IL 60637

and NBER

luigi.zingales@ChicagoBooth.edu
\end{abstract}




\section{$\underline{1 . \text { Introduction }}$}

In recent years, companies have come under increasing stakeholder pressure to pursue environmental and social goals. In 2019, \$20.6bn flowed to funds that explicitly divest from "nonsustainable” companies, more than 10 times the level a decade earlier (CBInsights (2020)). A recent survey suggests that $38 \%$ of Americans are currently boycotting at least one company, up from $26 \%$ only a year ago. ${ }^{1}$ In the last quarter of 2019, the term ESG (Environment, Social and Governance) was mentioned 357 times in earnings calls with CEOs versus only 49 times in the last quarter of 2016 (CBInsights (2020)).

At the same time a growing academic literature has argued that the usual presumption that firms should maximize profit or market value is no longer valid in a world where, as result of political failures either at the national or international level, externalities are not well-controlled. ${ }^{2}$ In particular, Hart and Zingales (2017) show that, to the extent a firm has a comparative advantage relative to individuals in producing a public good (or avoiding a public bad), a firm's shareholders may wish it to pursue social goals at the expense of profit. Consumers and workers may also be willing to pay a price for a firm to act in a socially responsible way.

In this paper we analyze theoretically whether pressure by stakeholders-consumers, workers, shareholders--is likely to achieve a socially desirable outcome. ${ }^{3}$ For concreteness we focus on the case of environmental harm caused by pollution, but the paper can be applied to any public good (or bad) where it is more efficient for a firm than for an individual to contribute to the formation (or preservation) of that public good. Using Hirschman's (1970) terminology, we can describe stakeholders' choices as exit versus voice. Investors or consumers can exercise their exit option by divesting from polluting companies or boycotting their products; or investors can use their voice by voting or engaging with management. (We focus on consumer boycotts, but argue that worker boycotts are conceptually similar.)

Under standard assumptions that agents are purely selfish, we are faced with a severe free rider problem (Olson (1965)): unless an agent is large, the direct benefit she receives from any exit

\footnotetext{
1 https://www.comparecards.com/blog/38-percent-boycotting-companies-political-pandemic-reasons/

2 See, for example, Baron (2007), Benabou and Tirole (2010), Edmans (2020), Elhauge (2005), Graff Zivin and Small (2005), Hart and Zingales (2007), Magill et al. (2015), Mayer (2018), Morgan and Tumlinson (2019), Schoenmaker and Schramade (2019), and Stout (2012).

${ }^{3}$ Our approach should not be confused with what Bebchuk and Tallarita (2020) call "stakeholderism." Stakeholderism refers to a situation where, in making business decisions, corporate leaders take into account the well-being of stakeholders (rather than just shareholders). In contrast, we are interested in analyzing how various stakeholders (including shareholders) can persuade companies to act in a more socially responsible manner.
} 
or voice decision is negligible. To explain social action, we assume - consistent with empirical evidence - that some investors and consumers are socially responsible in the sense that, when they make a decision, they put a positive weight $\lambda$ on the well-being of others affected by the decision. Other agents are purely selfish. In our model each firm can choose to be clean or dirty. A dirty firm produces environmental damage equal to $h .{ }^{4} \mathrm{~A}$ firm can avoid this damage by incurring an additional fixed cost $\delta$ and becoming clean. Given our simple set-up, it is socially desirable for a firm to become clean if and only if $h>\delta$.

We start by computing a competitive free entry equilibrium of this economy in the absence of any environmental concerns. We then study how the equilibrium changes when environmental concerns become an issue, depending on the strategy adopted by socially responsible stakeholders.

The two exit strategies are very similar in their impact. Divestment and boycotts cause the market value of a dirty firm to fall, leading some value-maximizing managers to switch to the clean technology. However, even if we ignore the marginal incentive to participate, both exit strategies will curb pollution in a less than proportional way: If ten percent of agents divest/boycott, less than ten percent of firms become clean (an observation already made by Heinkel et al. (2001) in the divestment context). The reason is that purely selfish agents will partially offset the effects of divestment/boycotting by increasing their investment/purchases in companies shunned by socially responsible agents. In both these cases the magnitude of the response depends on the slope of the demand curve, which is driven by agents' risk tolerance for investors and by the utility of the good for consumers.

When we look at the marginal incentives to participate in an exit strategy, we find that there is no simple relationship between the individual incentive to participate and the social incentive to create clean firms. Divesting or boycotting can lead to too little or too much exit from the perspective of a benevolent planner. However, when we focus on a level of the social responsibility parameter $\lambda$ close to what is observed in experimental evidence (Charness and Rabin (2003)), we find that the equilibrium level of exit is zero, unless pollution is extremely harmful.

\footnotetext{
${ }^{4}$ In this paper we assume $h$ to be known. This assumption is reasonable for standard pollution (for example PFOS or Particulate matter), but not for climate change. The uncertainty about $h$ generates an interesting risk management problem, analyzed in Andersson et al. (2016).
} 
We carry out our analysis under the assumption that exit decisions are common knowledge and agents can commit to them. As we explain in Section 6, in the absence of this assumption, both exit strategies become even less effective.

We then consider the voice strategy. While divesting and boycotting are fairly "institution free”, there are multiple ways to express voice, all of them highly regulated. As a starting point we abstract from any existing rule and reduce voice to a vote: shareholders are presented with the choice of whether the firm they own should be clean or dirty. The only time an individual shareholder's vote matters is when she is pivotal. Thus, as in Hart and Zingales (2017), we assume that shareholders will vote as if their vote were pivotal. A pivotal shareholder trades off the net social benefit from the clean technology, weighted by the shareholder's social parameter $\lambda$, against her own capital loss resulting from the choice of that technology. The net social benefit equals the reduced pollution minus the cost of generating that reduction. If shareholders are well-diversified, the personal capital loss is negligible. Thus, as long as $\lambda$ is positive, the first effect dominates and socially responsible shareholders vote in line with a benevolent planner's goal.

In our model we assume that all socially responsible agents have the same $\lambda$. If we extend the model to a distribution of the social responsibility parameter $\lambda$, the difference between exit and voice becomes even starker: all well-diversified investors with a positive $\lambda$ will vote for the social optimum, while only investors (consumers) with a high $\lambda$ will divest (boycott).

In practice, putting proposals up for a proxy vote is expensive and it will not be in the interest of atomistic investors to incur the cost of doing so. We argue that mutual funds can use engagement as a marketing strategy and show that socially responsible agents will be willing to invest in a Green Fund that is committed to promoting an environmental agenda.

Taken literally, our simple model suggests that for a sufficiently large number of (moderately) socially responsible agents, the voice strategy dominates the exit one. In practice, there are several real-world frictions that might attenuate or reverse this result. We discuss them in Section 7. In spite of these frictions, it remains true that, when agents choose voice, their individual incentives are aligned with the social incentive, whereas this is not the case when they choose exit.

There is a vast literature on socially responsible investment (SRI). Benabou and Tirole (2010), Kitzmueller and Shimshack (2012), and Christiansen et al. (2019) provide very useful overviews. On the divestment side, the first formal model is Heinkel et al. (2001). Our model of 
divestment is similar to theirs, but with the difference that they take as given that socially responsible investors refuse to hold shares of dirty companies, whereas we suppose that socially responsible investors make the divestment decision based on the impact this decision has. Pastor et al. (2020) extend the Heinkel et al. (2001) model to derive an ESG factor in an equilibrium asset-pricing model when investors have a taste for ESG (for another paper along similar lines, see Pedersen et al. (2019)). They do endogenize the divestment decision, but under the assumption that investors are purely selfish. Graff Zivin and Small (2005) and Morgan and Tumlinson (2019) suppose that investors value public goods and pay more for the shares of firms that bundle private and public goods; see also Aghion et al. (2020) and Bonnefon et al. (2019). However, each investor is selfish in that he values his consumption of the public good and not the utility from the public good accruing to others. Baron (2007), Chowdhry et al. (2019), Gollier and Pouget (2014), and Oehmke and Opp (2020) consider the impact of divestment, but for the case of large as opposed to atomistic investors

There is also a smaller literature on consumer boycotting (see Kitzmueller and Shimshack (2012) for a survey). Boycotts can be seen as a way to redistribute surplus (see Baron (2001)), or as a way to induce companies to provide a public good (see Bagnoli and Watts (2003) and Besley and Ghatak (2007)). In Bagnoli and Watts (2003) and Besley and Ghatak (2007), each consumer is selfish in that he values his consumption of the public good and not the utility from the public good accruing to others.

There is also a vast literature on corporate social responsibility. This literature argues that companies can or should have a purpose beyond profit or value maximization, including to act in a socially responsible manner (e.g., Edmans (2020), Magill et al. (2015), Mayer (2018), Schoenmaker and Schramade (2019), and Stout (2012)). In contrast, we assume that some individuals are socially responsible and derive the consequences for corporate behavior, depending on the tools these socially responsible individuals have at their disposal.

The rest of the paper proceeds as follows. Section 2 describes our assumption on socially responsible investors and consumers. Section 3 presents the model. Section 4 analyzes the exit strategy, Section 5 the voice one. Section 6 covers robustness and extensions, and Section 7 includes discussion and qualifications. Section 8 concludes. An appendix considers the case of a monopolistic firm. 


\section{Socially Responsible Investors and Consumers}

Responsible investing dates back at least as far as 1758, when the Philadelphia Yearly Meeting of the Society of Friends required its members to cease and desist from slaveholding (Brown (1988)). Consumer boycotting can be traced back even further to the vegetarianism of the Jain religion (Laidlaw (1995)). The rejection of slavery by the Quakers and of animal products by the Jains was on moral grounds, and thus did not lend itself to any economic calculus. This original perspective survives in much of the contemporary socially responsible investment literature. From Heinkel et al. (2001) to Hong and Kacperczy (2009), the early literature assumes that some investors simply do not want to own certain kinds of stocks. Such an approach is appropriate for "sinful” products, like tobacco, alcohol, or prostitution, but applies less well to social concerns that are less of a moral nature. Most investors are not morally against companies that emit $\mathrm{CO} 2$, they would just like these companies to emit less of it. Trinity Church was not morally against Walmart, it simply wanted Walmart not to sell assault weapons, and so on.

Some of the literature on socially responsible investment and consumption departs from the purely moral view. For example, Graff Zivin and Small (2005), Morgan and Tumlinson (2019), Bagnoli and Watts (2003), and Besley and Ghatak (2007) endogenize investor and consumer choice by assuming that an individual will value a share or good based on a combination of its private characteristics and the increased harm resulting from production. However, these authors assume that individuals consider only the personal disutility of the increased harm, ignoring the impact on others. As a result, in a large economy, there will be an extreme free rider problem, leading to a large deviation between private and social optimality. Sugden (1982) convincingly argues that such a model is inconsistent with the evidence on charitable contributions. One way to mitigate the free rider problem is to introduce a "warm glow" effect, along the line of Andreoni (1989). ${ }^{5}$ In a sense this is what Pastor et al. (2020) do in assuming an individual taste for green investment. However, in Pastor et al.'s approach, investors ignore their impact on others.

In our model socially responsible individuals are altruistic in the sense that they put some weight on the utility of others. There is growing evidence in support of this assumption: see Andreoni and Miller (2002), Charness and Rabin (2002), Riedl and Smeets (2017), Brodback et

\footnotetext{
${ }^{5}$ Another way is to introduce reciprocal behavior along the lines of Sugden (1984).
} 
al. (2019), and Bauer et al. (2020). ${ }^{6}$ We adopt Hart and Zingales (2017)'s formulation: we assume that, in making a decision, an individual puts weight $\lambda \in[0,1]$ on the welfare of those affected by the decision, where $\lambda$ reflects her degree of social responsibility. ${ }^{7}$ Consider, for example, the decision to wear a facemask to protect others from the risk of being infected, when this decision is not mandatory. An individual will compare the private cost of her decision, say 10, with the social benefit of the decision, say 50, where the latter is weighted by $\lambda$. If $\lambda>\frac{1}{5}$, she will wear a mask, if not she will not. ${ }^{8}$

With socially responsible individuals as we model them, the free rider problem is mitigated. This point can be illustrated with an example. Imagine that one individual by spending I dollars in water filtration can increase the water quality of a lake by $f(I)$, a benefit that is shared equally among $N$ individuals along the lake (including himself). If the individual is purely selfish he will maximize

$$
\frac{f(I)}{N}-I
$$

yielding the first order condition

$$
f^{\prime}(I)=N \text {. }
$$

As $N$ increases the underinvestment in the public good becomes more severe. Now consider the possibility that the individual is socially responsible, in the sense that he puts a positive weight $\lambda$ on the utility of others. He will then maximize:

$$
\frac{f(I)}{N}-I+\lambda(N-1) \frac{f(I)}{N},
$$

which yields the first order condition:

$$
f^{\prime}(I)=\frac{1}{\frac{1}{N}+\frac{N-1}{N} \lambda} .
$$

\footnotetext{
${ }^{6}$ Andreoni and Miller (2002) and Charness and Rabin (2002) find support for such preferences in lab experiments. A preference for socially responsible investment has also been found in field experiments in situations where this preference yields lower expected returns (Bauer et al. (2020)) and Riedl and Smeets (2017)). This preference is positively correlated with the degree of altruism (Broadback et al. (2018)). Such a preference is also consistent with the lower return of impact funds (Barber et al. (2020)).

${ }^{7}$ For similar formulations, see Acquatella (2020), Besley and Ghatak (2018), and Frydlinger and Hart (2019).

${ }^{8}$ Consistent with our model, U.S. counties with higher civic capital (which can be interpreted as a higher $\lambda$ ) wear masks more frequently and socially distance more; see Barrios et al. (2020).
} 
For $N$ large the above condition is

$$
f^{\prime}(I) \simeq \frac{1}{\lambda} .
$$

Not surprisingly, if $\lambda$ equals 1 we get the first best. If $\lambda<1$, we get more investment than in the purely selfish case, as long as $\lambda$ is bounded away from zero.

As in Hart and Zingales (2017), we assume that the socially responsible component enters at the time a decision is made, but not after the decision is made. ${ }^{9}$ We adopt this assumption to avoid double counting in the aggregate welfare function. With $\lambda=0$, the aggregate welfare function is equal to

$$
f(I)-I
$$

If we added the socially responsible component, the social welfare function would become

$$
f(I)-I+\lambda \frac{N-1}{N} f(I) .
$$

Thus, we would be double counting the utilities of the agents. However, in our context we do not think that incorporating the socially responsible component into the social welfare function would substantially change our results.

One interesting question is how broad is the group of people whose welfare enters a socially responsible individual's calculations: does it include people in one's neighborhood, the whole town, the whole country, or the whole world? The answer depends upon the socially responsible perspective of an individual and what she considers her relevant community. In this paper, we assume that the community includes everyone affected by the pollution.

\section{The Model}

\subsection{The case where pollution is not a problem}

Consider a three-date economy, as shown in Figure 1. At date 0 entrepreneurs can set up firms. Production decisions are made at date 1. Production and consumption take place at date 2. Entrepreneurs care only about money and have zero wealth. A fraction $0<\pi \leq 1$ of investors and of consumers are socially responsible, with $0<\lambda \leq 1$ (for simplicity, they all have the same $\lambda$ ).

\footnotetext{
${ }_{9}^{9}$ Acquatella (2020) and Frydlinger and Hart (2019) make a similar assumption.
} 
The rest are purely selfish $(\lambda=0)$. We assume that consumers and investors are different (investors do not consume firms’ output and consumers do not invest).

At date 0 pollution is not an issue (and is not expected to be an issue). There is a set-up cost $F$ for each firm, and each firm has a capacity constraint equal to one. After the set-up cost has been sunk, there is an additional cost of production $C$, incurred at date 2 . The expected value of $C$ is zero (up to the capacity constraint), but $C$ is uncertain. We suppose

$$
C=\varepsilon,
$$

where $\varepsilon$ is an aggregate shock, which is normally distributed with mean 0 and variance $\sigma^{2}$. The value of $\varepsilon$ is learned only at date 2. Note that we assume that the shock is an aggregate one to capture the limited risk bearing capacity of investors. However, there could also be an idiosyncratic component of the shock, which would explain why investors diversify their portfolios across firms.

Figure 1: Timeline

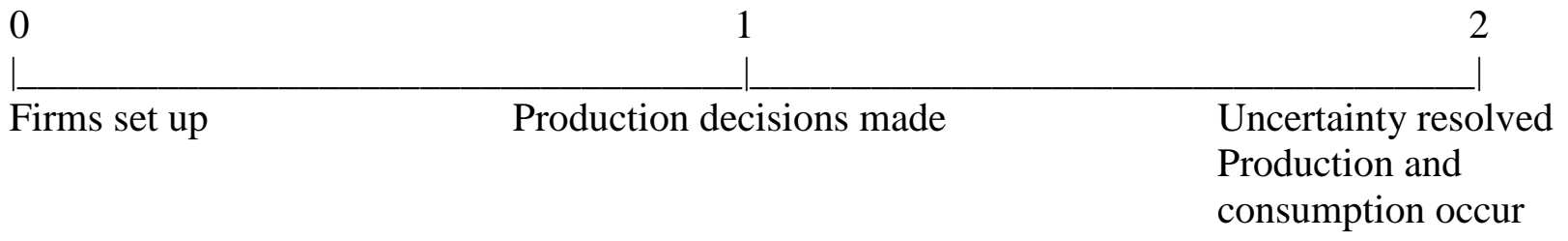

Entrepreneurs cover the date 0 set-up cost $F$ by issuing shares to investors. Investors have an exponential utility function

$$
U=-e^{-\gamma \omega}
$$

where $\omega$ is their final wealth. Investors hold the shares until date 2, when output is sold and profit is realized. However, at date 1 there can be some portfolio rebalancing.

We will study a competitive free entry equilibrium. We normalize the number of investors to be one. Of course, a one investor economy is not competitive. Therefore, in order to make the economy competitive, we will replicate it, as described below.

Assume that the product market consists of a homogenous good (whose origin can be easily determined, e.g., electricity). Normalize the number of consumers to be one, and suppose that the consumer's utility function is

$$
U=\rho q-\frac{1}{2} \tau q^{2}-p q
$$


where the third term is the cost of buying $q$ units of the good at price $p$. The maximization of this utility leads to the following demand curve,

$$
p=\rho-\tau q
$$

or

$$
q=\frac{\rho-p}{\tau} .
$$

Output is sold in a competitive market. Production decisions are made at date 1. Each firm produces up to its capacity constraint of one since price exceeds the expected value of $C$, which is zero. Thus total supply equals $N$, where $N$ is the number of firms set up at date 0 , and equilibrium in the date 2 goods market is given by

$$
N=\frac{\rho-p}{\tau} .
$$

Each firm's date 2 profit is

$$
\tilde{\Pi}=p-\varepsilon=\rho-\tau N-\varepsilon,
$$

and expected profit is

$$
\Pi=\rho-\tau N .
$$

Consider the investor's date 0 portfolio decision. Assume that the investor can borrow and lend at a zero rate of interest between dates 0 and 1 and dates 1 and 2 . In a free-entry equilibrium the market value of each firm at date 0 must be $F$ since otherwise firms would enter or exit. The total return for the investor at date 2 is therefore $x \tilde{\Pi}-x F$, where $x$ is his investment level and we normalize the investor's initial wealth to be zero. This return has a certainty equivalent given by

$$
\mathrm{CE}=x(\Pi-F)-\frac{1}{2} \gamma x^{2} \sigma^{2} .
$$

The investor's demand for shares at date 0 will be given by the $x$ that maximizes this certainty equivalent. Thus,

$$
x=\frac{\Pi-F}{\gamma \sigma^{2}} .
$$

In what follows we will assume that the investor holds all firms pro rata (his portfolio is fully diversified). 
(3.10) provides the total demand for firms' shares. The total supply is equal to $N$. Hence, for the stock market to clear at date 0 we must have

$$
\frac{\Pi-F}{\gamma \sigma^{2}}=N .
$$

Using (3.8), we obtain

$$
N=\frac{\rho-F}{\gamma \sigma^{2}+\tau} .
$$

This is the equilibrium number of firms that will set up at date $0 .{ }^{10}$ From now on we assume $\rho>F$, so $N>0$. For future reference, it is useful to derive the formula for the certainty equivalent at the optimal investment level $x$. This is obtained by substituting (3.10) into (3.9):

$$
\mathrm{CE}=\frac{1}{2} \frac{(\Pi-F)^{2}}{\gamma \sigma^{2}}=\frac{1}{2} \frac{(\rho-\tau N-F)^{2}}{\gamma \sigma^{2}}
$$

\subsection{Replica economy}

The economy as it stands is not competitive. To make it so we replicate the investor and consumer sectors. In the replica economy there are $r$ investors with the above investor preferences and $r$ consumers with the above consumer preferences. It is easy to see that the equilibrium number of firms will be $N r$, where $N$ is given by (3.12). For large $r$ each investor, consumer and firm is small relative to the aggregate economy and so has little influence on market prices. In other words, for large $r$ the economy is approximately perfectly competitive. ${ }^{11}$

In what follows we will have the replica economy in mind even though we will not always be explicit about it. When we study the effects of individual divestment, boycott and engagement decisions the replica economy will be particularly relevant.

\subsection{Pollution Becomes a Problem at Date 1}

\footnotetext{
${ }^{10}$ We ignore the fact that the solution to (3.12) may not be an integer. This will become unimportant in the replica economy described below when $r$ is large.

11 For details, see, e.g., Mas-Colell, Whinston, and Green (1995).
} 
Suppose that at date 1 pollution becomes a problem (to emphasize, this eventuality is unanticipated at date 0 ). ${ }^{12}$ Operating with the existing technology (which we will now label dirty), each firm produces harm $h>0$ to the environment at date 2 . We assume that the total harm from a single firm stays the same as the economy is replicated (replication simply makes the economy more competitive). Consistent with this, we suppose that each of the $r$ investors and the $r$ consumers experiences the harm from a single firm equally, that is, each individual's utility is reduced by $\frac{h}{2 r}$.

A firm can avoid polluting by incurring an additional fixed cost $\delta$ at date 1 ; this fixed cost comes out of date 2 profits. We call the firms that decide to pay this cost "clean". Thus, the cost of a clean $C$ firm is

$$
C^{C}=\delta+\varepsilon
$$

while the cost of a dirty $D$ firm is as before

$$
C^{D}=C=\varepsilon .
$$

If all investors and consumers are purely selfish $(\lambda=0)$, the existence of pollution will not change any production or investment decision significantly when $r$ is large: it will only reduce the utility of each agent by $\frac{N h}{2 r}$. The reason is simple. As $r \rightarrow \infty$, the pollution impact of any production and investment decision on each individual converges to zero. So, nobody internalizes the pollution externalities, as in Pastor et al. (2020). As we will see shortly, this is not the case when people are socially responsible. In this case, the outcome depends upon the strategy adopted by socially responsible investors and consumers. Before analyzing this, however, we need to consider what a benevolent planner would do, so that we have an appropriate benchmark.

\subsection{Benevolent Planner's Response to Environmental Damage}

As a benchmark, we derive a benevolent planner's solution in a world where all investors and consumers are purely selfish. The number of firms $N$ that entrepreneurs have set up at date 0 is given at date 1 . However, a benevolent planner can dictate what technology—clean or dirty—each

firm should adopt at date 1, that is, she can choose the proportion of clean firms $\phi=\frac{n_{c}}{N}$. Assume that this is the only instrument at the planner's disposal. That is, the planner chooses $\phi$ and then

12 We consider a rational expectations equilibrium in Section 6. 
lets the date 1 stock market and the date 2 product market clear. The question is at what level will she set $\phi$.

We suppose that the planner's objective is to maximize the sum of investor and consumer surplus, net of the harm imposed by pollution. Since the number of firms $N$ is given, consumer surplus is independent of $\phi$. The reason is that each firm produces one unit whether it is clean or dirty as long as $p$ exceeds the expected value of $\delta+\varepsilon$, which we will now assume:

$$
\rho-\tau N \geq \delta
$$

To derive investor utility we need to compute the investors' return at date 1 after the planner sets the proportion of clean firms at $\phi$ and investors freely re-optimize their investment choices.

Let the equilibrium prices of the two types of firms be $V_{c}$ and $V_{d}$. The gross return of a clean firm is $\delta$ less than that of a dirty firm. Thus, in order to ensure that (purely selfish) investors stay invested in both kinds of firms at date 1 we must have

$$
V_{c}=V_{d}-\delta
$$

The return of an investor at date 2 is

$$
x\left(\tilde{\Pi}-V_{d}\right)+x_{0}\left[\phi V_{c}+(1-\phi) V_{d}\right]-x_{0} F,
$$

where $x$ is her date 1 portfolio holding. The first term reflects the fact that the net return on her investment is $\tilde{\Pi}-V_{d}=\tilde{\Pi}-\delta-V_{c}$. In the second and third terms $x_{0}$ is the portfolio holding chosen at date 0 (given by (3.10)). The second term reflects the fact that a fraction $\phi$ of the firms the investor owns have become clean, and the third term is the original cost of the date 0 investment.

The certainty equivalent of this return is

$$
C E=x\left(\Pi-V_{d}\right)+x_{0}\left[\phi V_{c}+(1-\phi) V_{d}\right]-x_{0} F-\frac{1}{2} \gamma x^{2} \sigma^{2},
$$

and so the investor's date 1 choice of $x$ will satisfy

$$
x=\frac{\Pi-V_{d}}{\gamma \sigma^{2}} .
$$

The condition for date 1 stock market equilibrium is $x=N$, which combined with (3.11) yields

$$
V_{d}=F .
$$

Thus, 


$$
\begin{aligned}
C E & =\frac{(\Pi-F)^{2}}{2 \gamma \sigma^{2}}-\phi \delta x_{0} \\
& =\frac{(\Pi-F)^{2}}{2 \gamma \sigma^{2}}-\phi \delta \frac{(\Pi-F)}{\gamma \sigma^{2}} .
\end{aligned}
$$

By choosing $\phi N$ clean firms, the planner will cause the total amount of pollution to be $(1-\phi) N h$. Thus, the planner will maximize

$$
\left[\frac{(\Pi-F)^{2}}{2 \gamma \sigma^{2}}-\phi \delta \frac{(\Pi-F)}{\gamma \sigma^{2}}-(1-\phi) N h\right]
$$

with respect to $\phi$. Recall that $\Pi=\tau-\rho N$, which is independent of $\phi$. We obtain a bang-bang solution (either $\phi=0$ or $\phi=1$ ) depending on whether

$$
\delta \frac{(\Pi-F)}{\gamma \sigma^{2}}>\text { or }<N h .
$$

Using (3.11), this boils down to

$$
\delta>\text { or }<h .
$$

This is very intuitive. If $\delta>h$, the cost of avoiding pollution is bigger than the cost of pollution itself and thus all firms should use the dirty technology $(\phi=0)$. By contrast, if $\delta<h$ the cost of avoiding pollution is less than the cost of polluting and all firms should be clean $(\phi=1)$.

\section{$\underline{\text { 4. Exit Strategies }}$}

\subsection{Divesting}

We now analyze what happens when there is no planner (or government) and social action is left to individual investors or consumers. We consider first the strategy of divestment by investors. Assume that a mass $\mu \leq \pi$ of socially responsible investors announce that they will hold shares only in $C$ firms. We suppose that this announcement is visible and that investors can commit to their divestment decision (we return to this issue in Section 6). We want to determine whether this outcome can be sustained. To this end we first derive the product market and capital market equilibrium under the assumption that a mass $\mu$ of socially responsible investors will divest from dirty firms. Then, we check that each socially responsible investor does indeed want to divest (that is, we are at a Nash equilibrium). In this subsection we assume that there is no consumer boycott. 
We suppose that at date 1 firms are run by value-maximizing managers. One can imagine that (before there were any environmental concerns) initial entrepreneurs designed an incentive scheme to encourage managers to maximize market value at date 1 in order to obtain the highest valuation at date 0 . Note that initial entrepreneurs are not well-diversified and so they want to maximize the value of their own company, not the joint value of all companies, as the common ownership literature suggests (see Azar et al. (2018)) ${ }^{13}$.

Value maximization implies that in the date 1 equilibrium $\mathrm{C}$ and $\mathrm{D}$ firms must have the same value $V$, otherwise there would be switching. ${ }^{14}$ Let $n_{c}$ be the number of clean firms and $n_{d}=N-n_{c}$ the number of dirty firms.

For divestors, the analogy of (3.10) is

$$
x=\frac{\Pi-\delta-V}{\gamma \sigma^{2}},
$$

since C firms yield expected profits $\Pi-\delta$, rather than $\Pi$, and cost V. Since divestors represent a mass $\mu$ of investors, their demand for clean firms is

$$
\mu x=\mu\left(\frac{\Pi-\delta-V}{\gamma \sigma^{2}}\right) .
$$

The rest of the market will not invest in clean firms since they are less profitable, but equally expensive. Hence, (4.2) represents the total demand for clean firms, and we must have

$$
\mu\left(\frac{\Pi-\delta-V}{\gamma \sigma^{2}}\right)=n_{c} .
$$

\footnotetext{
${ }^{13}$ We consider the possibility of socially responsible entrepreneurs in Section 6. In this paper we do not discuss how incentive contracts can affect the ESG decision of managers; on this, see Davies and Van Wesep (2018).
}

\footnotetext{
${ }^{14}$ An interesting question is whether a purely selfish investor could take advantage of the fact that clean and dirty firms have the same price, but different expected profitability, by short selling one and using the proceeds to invest in the other. The feasibility of this strategy depends on whether socially responsible investors are willing to lend shares to short sellers and whether they are willing to accept borrowed shares as "bona fide" clean shares. In our model, where socially responsible investors care about their impact, the answer to both questions is negative. A socially responsible investor, who accepts a lower return for a greater cause, would be foolish to lend his shares to a speculator who undoes his strategy without fully compensating him. The same is true for an investor buying lent shares.
} 
Similarly, the demand for dirty firms will be given by

$$
(1-\mu)\left(\frac{\Pi-V}{\gamma \sigma^{2}}\right),
$$

which must be equal to $n_{d}$ :

$$
(1-\mu)\left(\frac{\Pi-V}{\gamma \sigma^{2}}\right)=n_{d} .
$$

Adding (4.3) and (4.5) yields

$$
\Pi-V-\mu \delta=N \gamma \sigma^{2}
$$

We know from (3.11) that $N \gamma \sigma^{2}=\Pi-F$, and therefore

$$
V=F-\mu \delta^{15}
$$

Substituting back into (4.3), we obtain

$$
\begin{aligned}
n_{c} & =\mu\left(\frac{\Pi-F-\delta(1-\mu)}{\gamma \sigma^{2}}\right) \\
& =\mu N-\frac{\mu \delta(1-\mu)}{\gamma \sigma^{2}} .
\end{aligned}
$$

\section{(4.8) is illustrated in Figure 2. ${ }^{16}$}

Figure 2: Impact of $\mu$ on percentage of clean firms

In drawing this graph we assumed the following values of the parameters: $\mathrm{N}=10, \delta=0.04, \sigma^{2}=0.2$, and $\gamma=0.02$.

\footnotetext{
${ }^{15}$ We assume that $F>\delta$, so that $V>0$. Otherwise firms might choose not to produce at all.

${ }^{16}$ A similar equation and figure can be found in Heinkel et al. (2001). The solution to (4.8) may not be an integer. We ignore this issue, but imposing an integer constraint would affect our calculation of the marginal incentive to divest below. We discuss this in Section 6.
} 


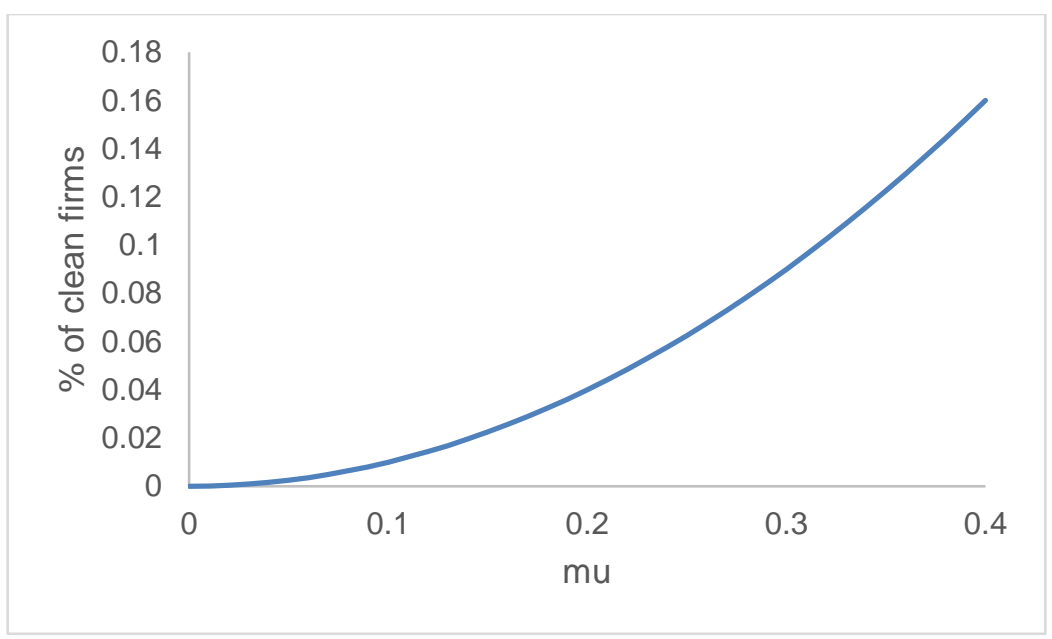

At this point it is helpful to provide some intuition. To understand (4.7), note that divestment leads to a fall in the demand for dirty firms' shares, causing $V$ to fall. If $V$ fell by $\delta$, clean firms would have the same net return as dirty firms previously, while dirty firms would have a higher net return. As a result, the demand for shares would exceed the supply. Hence $V$ must fall by less than $\delta$, indeed by $\mu \delta$ according to (4.7).

(4.7) also throws light on (4.8). If $V$ fell by $\delta$, the demand for clean firms' shares would be in proportion to the number of divestors since divestors would invest as much as before. However, since $V$ falls less, the demand for clean shares is lower and the number of clean firms is less than proportional to the number of divestors. Indeed $n_{c}$ is quadratic in $\mu$.

(4.8) implies that the marginal impact of divestment is increasing in $\mu$. If $N<\frac{\delta}{\gamma \sigma^{2}}$, we have a corner solution: the number of clean firms $n_{c}=0$ in a neighborhood of $\mu=0$ and, for low $\mu$, the marginal impact of $\mu$ on $n_{c}$ is zero. Note that a corner solution will occur when either the risk aversion $\gamma$ is low or the variance of returns $\sigma^{2}$ is low (or both). Under these conditions it is a (Nash) equilibrium for no socially responsible investor to divest: starting at $\mu=0$, purely selfish investors will absorb any divested stock with minimal price impact and as a result no firms will become clean. 
Conversely, $n_{c}>0$ if $N>\frac{\delta(1-\mu)}{\gamma \sigma^{2}}$. Thus, divesting will have a positive impact when the mass of divesting investors $\mu$ is close to 1 , the cost of the clean technology $\delta$ is small, the risk bearing capacity of investors is low, or the variance of returns is high.

From now on we assume that we are at an interior solution for any $\mu>0$, that is,

$$
N>\frac{\delta}{\gamma \sigma^{2}}
$$

We next determine whether a socially responsible investor wants to divest when (4.9) holds. As a first step, we compare the certainty equivalent of a divestor with the certainty equivalent of a nondivestor. We then bring in the environmental impact of divestment.

The payoff of a nondivestor is given by

$$
x \tilde{\Pi}+\left(x_{0}-x\right) V-x_{0} F,
$$

since they invest only in high return dirty firms.

The certainty equivalent of (4.10) is

$$
x(\Pi-V)+x_{0}(V-F)-\frac{1}{2} \gamma x^{2} \sigma^{2}
$$

and the $x$ that maximizes (4.11) is

$$
x=\frac{\Pi-V}{\gamma \sigma^{2}} .
$$

Substituting (4.12) and (3.10) into (4.11) and using (4.7), we obtain the following expression for the CE of a nondivestor:

$$
C E_{n d}=\frac{1}{2 \gamma \sigma^{2}}(\Pi-F+\mu \delta)^{2}-\mu \delta \frac{\Pi-F}{\gamma \sigma^{2}} .
$$

Carrying out the same exercise for a divestor yields

$$
C E_{d}=\frac{1}{2 \gamma \sigma^{2}}(\Pi-F-\delta+\mu \delta)^{2}-\frac{\mu \delta}{\gamma \sigma^{2}}(\Pi-F) .{ }^{17}
$$

\footnotetext{
${ }^{17}$ Note that (4.9) implies $n_{c}>0$, which in turn, given (4.3), implies $\Pi-F-\delta+\mu \delta>0$.
} 
Thus by divesting an investor loses

$$
C E_{n d}-C E_{d}=\frac{\delta}{2 \gamma \sigma^{2}}(2 \Pi-2 F-\delta(1-2 \mu)) .
$$

A socially responsible investor will compare this loss with the effect her divestment has on the environment and on other people's utilities. To keep track of this effect we have to take seriously that we are in a replica economy. In the replica economy there are $r$ investors, $\mu r$ of whom divest; $r$ consumers; and $\mathrm{Nr}$ firms set up in the free entry equilibrium, of which $n_{c} r$ choose to become clean at date 1 , where $n_{c}$ is given by (4.8). The effect of one investor's divestment decision is composed of two elements: the impact on the environment and the impact on other investors and on consumers. Investors are optimizing and so, by the envelope theorem, a small change in the market value of firms caused by one investor divesting will have a second order effect on other investors. Consumers will be unaffected because total supply equals $N$, independent of the mix of clean and dirty firms. Thus, we are left with the effect on the environment.

Currently $\mu r$ investors are divesting. If one investor stops divesting $\mu$ changes from $\mu$ to $\mu-\frac{1}{r}$, i.e., $\Delta \mu=-\frac{1}{r}$. The number of clean firms changes from $n_{c} r$ to $\left(n_{c}+\frac{\partial n_{c}}{\partial \mu} \Delta \mu\right) r$, plus some second order terms. That is, as $r \rightarrow \infty$, the change in the number of clean firms is

$$
\frac{\partial n_{c}}{\partial \mu}\left(-\frac{1}{r}\right) r=-\frac{\partial n_{c}}{\partial \mu}=-N+\frac{\delta(1-2 \mu)}{\gamma \sigma^{2}},
$$

where we use (4.8). So the damage created by the investor's decision not to divest is $\left[N-\frac{\delta(1-2 \mu)}{\gamma \sigma^{2}}\right] h$, which the investor weights by her socially responsible parameter $\lambda$. She then compares this to the expression in (4.15). We may conclude that a socially responsible investor will be willing to stay divested if

$$
\frac{\delta}{2 \gamma \sigma^{2}}(2 \Pi-2 F-\delta(1-2 \mu)) \leq \lambda h\left[N-\frac{\delta(1-2 \mu)}{\gamma \sigma^{2}}\right],
$$

which can be rewritten as 


$$
\delta(2 \Pi-2 F-\delta(1-2 \mu)) \leq 2 \lambda h\left[N \gamma \sigma^{2}-\delta(1-2 \mu)\right] .
$$

Using (3.11), we can rewrite (4.18) as

$$
\delta N-\frac{\delta^{2}(1-2 \mu)}{2 \gamma \sigma^{2}} \leq \lambda h N-\frac{\lambda h \delta(1-2 \mu)}{\gamma \sigma^{2}}
$$

or, rearranging,

$$
(\lambda h-\delta)\left(N-\frac{\delta}{\gamma \sigma^{2}}\right)+\frac{\mu \delta}{\gamma \sigma^{2}}(2 \lambda h-\delta) \geq \frac{\delta^{2}}{2 \gamma \sigma^{2}}
$$

Inequality (4.20) is the condition for a socially responsible investor to be willing to keep divesting. We can use (4.20) to characterize the (Nash) equilibrium values of $\mu$.

\section{Proposition 1:}

If the LHS of (4.20) is less than the RHS at $\mu=0$, then $\mu=0$ is an equilibrium.

If the LHS of (4.20) is greater than the RHS at $\mu=\pi$, then $\mu=\pi$ is an equilibrium.

If the LHS of (4.20) is equal to the RHS at $0 \leq \hat{\mu} \leq \pi$, then $\mu=\hat{\mu}$ is an equilibrium ${ }^{18}$.

To gain further insight, it is helpful to distinguish between the cases $2 \lambda h>\delta$ and $2 \lambda h<\delta$. Suppose that people are not strongly altruistic, in the sense that $\lambda$ is significantly less than $1 / 2$. This assumption is consistent with Charness and Rabin (2002), who find than an average $\lambda$ of 0.25 best fits the data.

Then, $2 \lambda h>\delta$ is a case where pollution is very inefficient, while $2 \lambda h<\delta$ is a case where pollution is not very inefficient. With this intuition in mind, let us analyze the two cases.

\section{Case1: $2 \lambda h>\delta$}

The LHS of (4.20) is increasing in $\mu$. Figures 3 a-c illustrate the possibilities. In $3 a, \mu=\pi$ is the unique equilibrium. In $3 \mathrm{~b}$, there are three equilibria, $\mu=0, \mu=\hat{\mu}$, and $\mu=\pi$. In $3 \mathrm{c}, \mu=0$ is the unique equilibrium.

\footnotetext{
${ }^{18}$ The conclusion that $0 \leq \hat{\mu} \leq \pi$ is an equilibrium when the LHS of (4.20) equals the RHS is strictly speaking only true in the limit economy. If $r$ is large and finite, second order terms may determine whether any deviation from $\mu=\hat{\mu}$ is in an individual investor's interest. This warrants further investigation.
} 
Case 2: $2 \lambda h<\delta$.

Now the LHS of (4.20) is decreasing in $\mu$ and is negative when $\mu=0$. The situation is as in Figure 3d The unique equilibrium is $\mu=0$.

Figure 3: Possible Cases
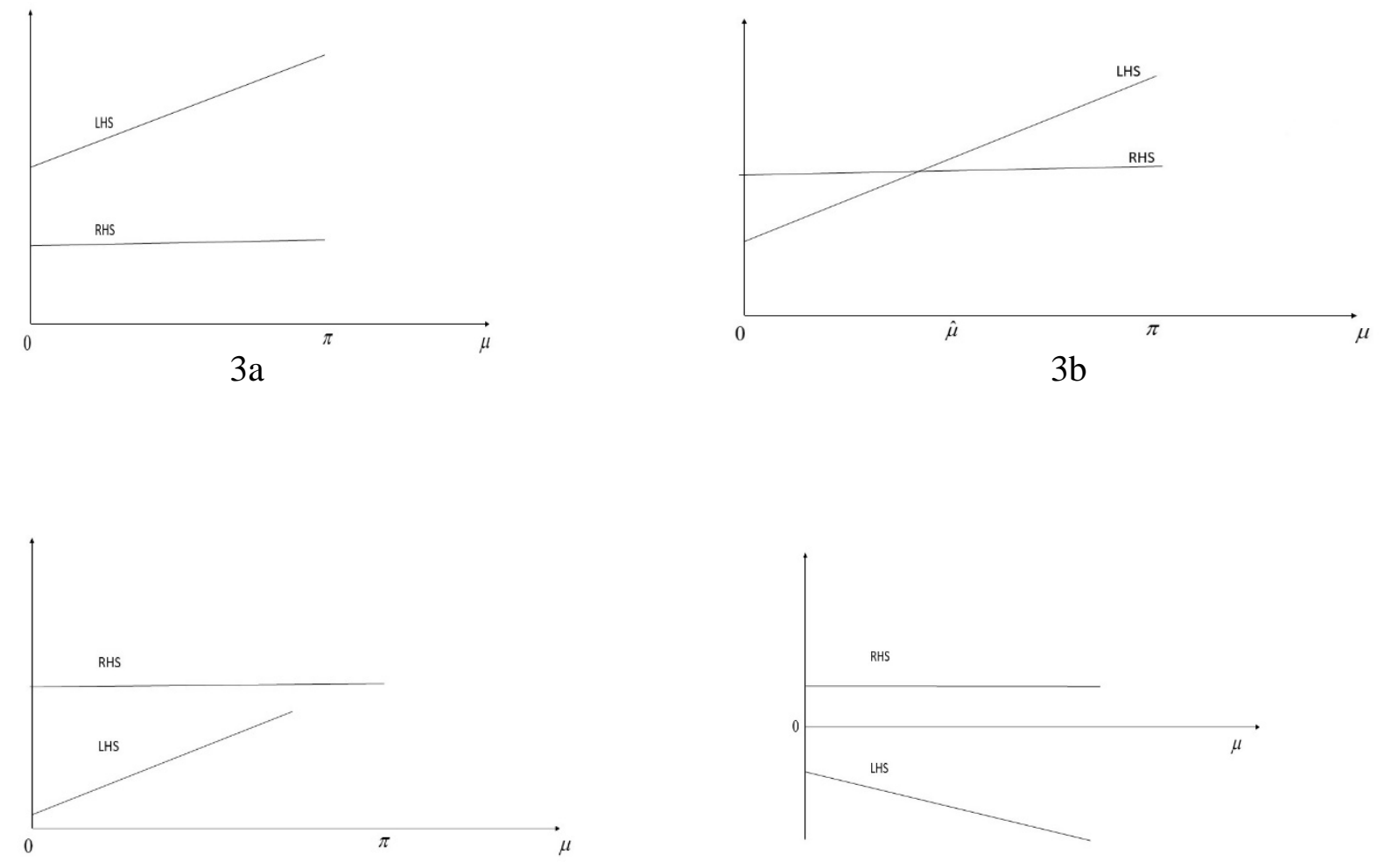

3c

3d

Two conclusions follow from our discussion. First, when $h>\delta$ the social optimum is $n_{c}=N$ (see Section 3.4), and so we want all socially responsible investors to divest. (Even if they do, according to (4.8) we have $n_{c}=\pi N-\frac{\pi \delta(1-\pi)}{\gamma \sigma^{2}}<\pi N<N$.) Yet, $\mu=\pi$ may not be an equilibrium. Indeed, if pollution is not too inefficient and $\lambda$ is not very large, then $2 \lambda h<\delta$ and $\mu=0$ is the only equilibrium: there is no divestment at all. 
Even if $2 \lambda h>\delta$, there is no guarantee that divestment will occur. It is quite possible that the LHS of (4.20) is less than the RHS at $\mu=0$ (this will be true if $N \simeq \frac{\delta}{\gamma \sigma^{2}}$ ). Thus, for small $\mu$, Figure 3c applies and the unique equilibrium is $\mu=0$.

The first conclusion then is that there will typically be underdivestment when $h>\delta$.

The second conclusion is that in the (perhaps unlikely) case where investors are very socially responsible, there can be excessive divestment when $h<\delta$. When $h<\delta, n_{c}=0$ is socially optimal. But if $\lambda=1$ and $h>\frac{3}{4} \delta$, then we are again in Case 1 and it is easy to see that Figure 3b can apply if $\pi$ is large enough (the LHS of (4.20) is less than zero at $\mu=0$ and greater than zero at $\mu=1$ ). Hence, $\mu=\pi$ is an equilibrium under these conditions: there can be too many clean firms.

The intuition for both underinvestment and overinvestment is roughly as follows. As (4.8) shows, the number of clean firms is quadratic in $\mu$ and the marginal impact of divestment on $n_{c}$ is increasing in $\mu$. As a result, low $\mu$ equilibria can be sustained when $h>\delta$ and high $\mu$ equilibria can be sustained when $h<\delta$.

The above analysis is under the assumption that $N>\frac{\delta}{\gamma \sigma^{2}}$. As we noted earlier, if $N<\frac{\delta}{\gamma \sigma^{2}}, \mu=0$ is always an equilibrium, since $n_{c}=0$ in a neighborhood of $\mu=0:$ investors have no incentive to divest. Indeed if $N<\frac{\delta(1-\pi)}{\gamma \sigma^{2}}$, then $\mu=0$ is the only equilibrium, since $n_{c}=0$ for $\mu \leq \pi$.

In closing this subsection, let us note how our theoretical results compare with the evidence. Most of the empirical literature on divestment focuses on institutional investors, not individuals, whose choices are generally not observable (but see Hartzmark and Sussman (2019)). Teoh et al. (1999) study one of the broadest divestment campaigns --the one against the apartheid regime in South Africa-- and find no impact on stock prices.

\subsection{Consumer Boycotts}


In this section we ignore the possibility of divesting and focus on a different form of exit: consumer boycotts. For boycotts to be possible, we need to assume that consumers know the technology behind the good they buy: they can tell whether the good is produced by a clean firm or a dirty firm. We suppose that boycotting decisions are common knowledge and that consumers can commit to them (but see Section 6). As in previous sections we suppose that a boycott is not anticipated at date 0 when firms are set up, but only becomes a factor at date 1 . Thus, $N$ is predetermined at date 1 and is given by (3.12).

Consider the replica economy where there are $r$ consumers. Suppose that a fraction $\pi$ of them are socially responsible, with parameter $\lambda$. As before, we start by assuming that a fraction $\theta \leq \pi$ of consumers will boycott the dirty product and then derive the equilibrium value of $\theta$. Boycotters buy only clean items at a price $p_{c}$. The other consumers are either indifferent about what they buy (if $p_{c}=p_{d}$ ) or buy only dirty items (if $p_{d}<p_{c}$ ). We will see that $p_{d}<p_{c}$. Thus, a fraction $\theta$ of the demand will be for clean products and a fraction $(1-\theta)$ for dirty products.

Consider an equilibrium with $n_{c}$ clean firms and $n_{d}$ dirty firms, where $n_{d}=N-n_{c}$. The equilibrium in the output market requires that

$$
\theta\left(\frac{\rho-p_{c}}{\tau}\right)=n_{c},(1-\theta)\left(\frac{\rho-p_{d}}{\tau}\right)=n_{d}
$$

where $p_{c}$ and $p_{d}$ are the prices of clean and dirty goods, respectively.

Solving these equations yields,

$$
\begin{aligned}
& p_{c}=\frac{\theta \rho-\tau n_{c}}{\theta}, \\
& p_{d}=\frac{(1-\theta) \rho-\tau n_{d}}{1-\theta} .
\end{aligned}
$$

In an interior equilibrium the expected date 1 profit of clean and dirty firms must be the same, since otherwise the lower profit firms would have a lower market value (since investors must be induced to hold the shares), and a dirty firm would have the incentive to become clean or vice versa. Hence,

$$
\Pi_{c}=p_{c}-\delta=\Pi_{d}=p_{d}
$$

Substituting the value of $p_{c}$ and $p$ we have 


$$
\frac{\theta \rho-\tau n_{c}}{\theta}-\delta=\frac{(1-\theta) \rho-\tau n_{d}}{1-\theta}
$$

and using $n_{d}=N-n_{c}$ we can rewrite this as

$$
\begin{aligned}
& n_{c}=\theta \mathrm{N}-\frac{\delta \theta(1-\theta)}{\tau} \\
& n_{d}=(1-\theta) \mathrm{N}+\frac{\delta \theta(1-\theta)}{\tau} .
\end{aligned}
$$

Note that the first equation in (4.25) is very similar to (4.8). ${ }^{19}$ The impact of boycotting is similar to the impact of divesting. Boycotting will be effective when either the mass of boycotters is close to 1 or the cost of the clean technology is small relative to slope of the demand curve. As for divestors, boycotters impact the equilibrium level of $\mathrm{C}$ firms less than proportionally.

If $N<\frac{\delta}{\tau}$, we have a corner solution: the number of clean firms $n_{c}=0$ in a neighborhood of $\theta=0$ and, for low $\theta$, the marginal impact of $\theta$ on $n_{c}$ is zero. Note that this will be the case when the slope of the demand curve is low. Under these conditions it is a (Nash) equilibrium for no socially responsible consumer to divest: starting at $\theta=0$, purely selfish consumers will absorb any goods boycotters shun with minimal price impact and as a result no firms will become clean.

For small $\theta$, we have an interior solution with a positive number of clean firms $\left(n_{c}>0\right)$ if and only if $N>\frac{\delta}{\tau}$. From now on, we assume

$$
N>\frac{\delta}{\tau}
$$

Suppose that one of the socially responsible consumers stops boycotting. When she was boycotting dirty products, she was maximizing her utility $\rho q-\frac{1}{2} \tau q^{2}-p_{c} q$, yielding $q=\frac{\rho-p_{c}}{\tau}$. This purchase generates a utility of $\left(\rho-p_{c}\right) \frac{\rho-p_{c}}{\tau}-\frac{1}{2} \tau\left(\frac{\rho-p_{c}}{\tau}\right)^{2}=\frac{1}{2 \tau}\left(\rho-p_{c}\right)^{2}$. When she

${ }^{19}$ As for (4.8), the solution to (4.25) may not be an integer. We ignore this issue, but imposing an integer constraint would affect our calculation of the marginal incentive to boycott below. We discuss this in Section 6. 
stops boycotting she maximizes $\rho q-\frac{1}{2} \tau q^{2}-p_{d} q$ and so her utility becomes $\frac{1}{2 \tau}\left(\rho-p_{d}\right)^{2}$. Thus, the change is

$$
\frac{1}{2 \tau}\left[\left(\rho-p_{d}\right)^{2}-\left(\rho-p_{c}\right)^{2}\right]=\frac{1}{2 \tau}\left[\left(2 \rho-p_{d}-p_{c}\right)\left(p_{c}-p_{d}\right)\right] .
$$

At the same time, the socially responsible consumer bears a cost of not boycotting due to her internalizing a fraction of social welfare. As in the divestment case the effect of her stopping her boycott on other consumers' and investors' utility is zero by the envelope theorem. But there is a negative effect on the environment equal to $h \frac{\partial n_{c}}{\partial \theta}$, which will have weight $\lambda$ in her utility function. Thus, a boycott is sustainable if and only if

$$
\frac{1}{2 \tau}\left(2 \rho-p_{d}-p_{c}\right)\left(p_{c}-p_{d}\right) \leq \lambda h \frac{\partial n_{c}}{\partial \theta} .
$$

We can rewrite this as

$$
\frac{1}{2 \tau}\left(2 \rho-\left[\rho-\frac{\tau n_{c}}{\theta}+\rho-\frac{\tau n_{d}}{1-\theta}\right]\right)\left(\frac{\tau n_{d}}{1-\theta}-\frac{\tau n_{c}}{\theta}\right) \leq \lambda h\left[N-\frac{\delta}{\tau}(1-2 \theta)\right],
$$

where we use (4.25). The LHS of (4.29) can be simplified (again using (4.25)) to

$$
\frac{\delta}{2}\left(2 N-\frac{\delta}{\tau}+\frac{2 \delta \theta}{\tau}\right)
$$

and so (4.29) becomes

$$
\frac{\delta}{2}\left(2 N-\frac{\delta}{\tau}+\frac{2 \delta \theta}{\tau}\right) \leq \lambda h\left[N-\frac{\delta}{\tau}+\frac{2 \delta \theta}{\tau}\right]
$$

which can be rewritten as

$$
\tau(\delta-\lambda h) N \leq(2 \theta-1) \delta\left(\lambda h-\frac{\delta}{2}\right) .
$$

We can divide the cases up as in Section 4.1.

Case $1: 2 \lambda h>\delta$.

Figure 4: Possible Equilibria of the boycotting case 


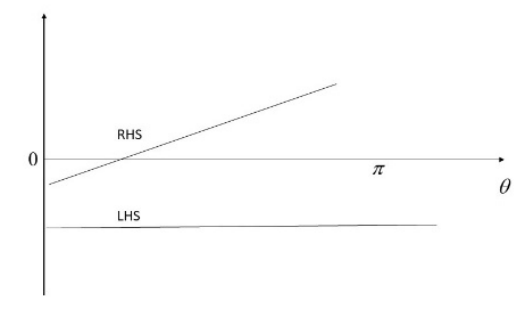

$4 \mathrm{a}$

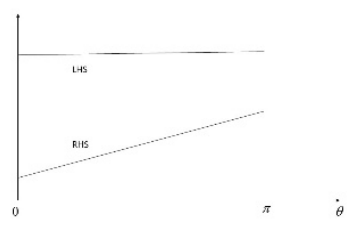

4c

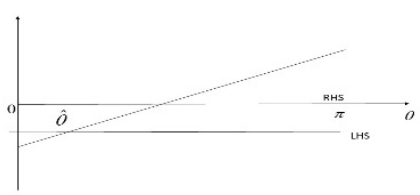

$4 \mathrm{~b}$

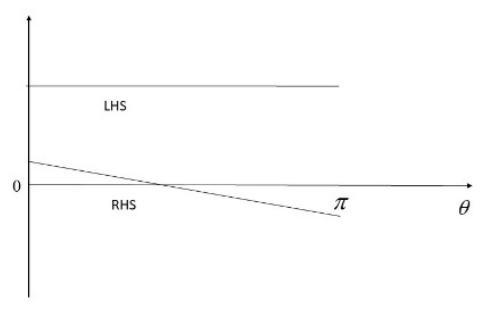

$4 d$

The RHS of (4.32) is increasing in $\theta$. Figures 4a-c illustrate the possibilities. In 4a, $\theta=\pi$ is the unique equilibrium. In $4 \mathrm{~b}$, there are three equilibria $\theta=0, \theta=\hat{\theta}$, and $\theta=\pi \cdot{ }^{20} \operatorname{In} 4 \mathrm{c}, \theta=0$ is the unique equilibrium.

Case $2: 2 \lambda h<\delta$

The RHS of (4.32) is decreasing in $\theta$ and is less than the LHS at $\theta=0$, since LHS of (4.32) $=$ $\tau \mathrm{N}(\lambda h-\delta)>\delta(\lambda h-\delta)>\delta\left(\lambda h-\frac{\delta}{2}\right)=$ RHS of (4.32) at $\theta=0$, where the first inequality follows from (4.26). The situation is as in Figure $4 \mathrm{~d}$. The unique equilibrium is $\theta=0$.

As with divestment, there can be too little boycotting or too much. First, when $h>\delta$ the social optimum is $n_{c}=N$ (see Section 3.4), and so we want all socially responsible consumers to boycott. Yet, $\theta=\pi$ may not be an equilibrium. Indeed, if pollution is not too inefficient and $\lambda$ is not very large, then $2 \lambda h<\delta$ and $\theta=0$ is the only equilibrium: there is no boycotting at all.

${ }^{20}$ With the same caveat noted in footnote 18. 
On the other hand, there could be too much boycotting. Suppose $h<\delta$ and $\lambda=1$. If $h>\frac{3}{4} \delta$ we are in Case 1. But it is easy to see that the LHS of (4.32) exceeds the RHS at $\theta=0$ (by (4.26)); however, the LHS of (4.32) is less than the RHS at $\theta=1$ if $\tau N$ is close to $\delta$. Hence, Figure $2 \mathrm{~b}$ applies and $\theta=\pi$ will be an equilibrium if $\pi$ is large enough.

The intuition for the distortions is as before. From (4.25), $n_{c}$ is quadratic in $\theta$ and thus the marginal impact of boycotting is increasing in $\theta$.

The above analysis is under the assumption $N>\frac{\delta}{\tau}$. As we noted earlier, if $N<\frac{\delta}{\tau}, \theta=0$ is always an equilibrium, since $n_{c}=0$ in a neighborhood of $\theta=0$ : consumers have no incentive to boycott. Indeeed, if $N<\frac{\delta(1-\pi)}{\tau}$, then $\theta=0$ is the only equilibrium since $n_{c}=0$ for $\theta \leq \pi$.

The most important takeaway from this section is that what we said about divestment is true of boycotts as well. If pollution is not too inefficient and people are not strongly altruistic, we will be in Case 2 and the equilibrium level of boycotting equals zero.

Unlike for divestment, there is some evidence that consumer boycotts have an impact on the stock price of targeted companies (Pruitt and Friedman (1986)). A possible explanation is that the slope of the demand curve for goods is larger than the slope of the demand curve for shares.

\section{Voice}

Socially responsible investors can also engage with management. We assume that all investors continue to buy dirty as well as clean firms - i.e., they do not discriminate. (To put it another way they do not both engage and divest.) While divesting and boycotting are fairly "institution free" strategies, engaging is not. Therefore, to analyze the engagement strategy we first look at the voting decisions of atomistic shareholders, assuming that environmental proposals are exogenously put up for a proxy vote. Later we will consider the role of mutual funds in facilitating engagement.

\subsection{Voting}

Suppose there are $v N$ clean firms and $(1-v) N$ dirty firms at date 1 . Assume that a vote takes place whether one of the dirty firms should become clean. As mentioned in the Introduction, we 
follow Hart and Zingales (2017) in assuming that each shareholder votes as if she were pivotal, since this is the only time her vote matters.

Given $v N$ clean firms, the resulting stock market equilibrium will be as in Section 3.4, where the benevolent planner chose the number of clean firms. That is, $V_{c}=F-\delta$ and $V_{d}=F$, and the certainty equivalent of each investor is given by (3.27):

$$
C E=\frac{(\Pi-F)^{2}}{2 \gamma \sigma^{2}}-v \delta \frac{(\Pi-F)}{\gamma \sigma^{2}} .
$$

It is important to recognize that the formula (5.1) reflects our assumption that investors are well-diversified (see the discussion of (3.27)). As a result the capital loss incurred by any one firm becoming dirty will be shared equally by $r$ investors. We discuss the case of concentrated ownership in Section 5.3.

Suppose that one additional dirty firm becomes clean as a result of the vote. This will cause CE to change by $\frac{\partial C E}{\partial v} \Delta v$. But in the replica economy $\Delta v=\frac{1}{N r}$, and so the change in CE converges to zero as $r \rightarrow \infty$.

The remaining effect of bringing about an extra clean firm consists of two elements: the impact on the environment and the impact on the wealth of other investors (the effect on consumers is zero, since the supply of output remains at $N$ ). The impact on the environment is

$$
h \frac{\partial\left(r n_{c}\right)}{\partial v} \Delta v=h r N \Delta v=h
$$

because $n_{c}=v N$ and $\Delta v=\frac{1}{N r}$.

The impact on other investors' wealth is no longer zero (the envelope theorem does not apply since firms that are pressed to choose clean by engaged shareholders are not maximizing value), but is now given by

$$
\frac{\partial[(r-1) C E]}{\partial v} \Delta v=\frac{(r-1)}{N r} \frac{\partial C E}{\partial v}=-\frac{(r-1)}{N r} \delta \frac{(\Pi-F)}{\gamma \sigma^{2}},
$$

which converges to

$$
-\delta \frac{(\Pi-F)}{N \gamma \sigma^{2}}
$$

as $r \rightarrow \infty$. 
Summing the two effects and weighting them by $\lambda$ yields the conclusion that bringing about an extra clean firm is desirable for the investor if

$$
\lambda\left(h-\delta \frac{(\Pi-F)}{N \gamma \sigma^{2}}\right)>0 .
$$

Since $\lambda>0$ and by (3.11) $N=\frac{\Pi-F}{\gamma \sigma^{2}}$, we may conclude that a socially responsible investor will vote "clean" (that is, to make the dirty firm clean) if and only if $h>\delta$, which is the same criterion used by the planner. In other words, if $h>\delta$, all socially responsible investors will vote clean, while if $h<\delta$ all investors will vote dirty.

Note that (5.5) applies regardless of $\lambda$, as long as $\lambda>0$. Thus, if instead of having a fraction of investors with the same $\lambda$, we have a distribution of investors with different $\lambda$ 's, then all the investors with $\lambda>0$ will vote as the benevolent planner would. Hence, as long as the majority of investors are a little socially responsible, voting will deliver the social optimum. If the majority of investors are purely selfish, however, and a vote requires majority support to be effective, engagement by socially responsible shareholders will have no impact.

\subsection{Engaging through an intermediary}

Putting proposals up for a proxy vote is expensive. It will not be in the interest of atomistic investors to incur the cost of doing so, and management is unlikely to take the lead. By contrast, mutual funds can use engagement as a marketing strategy (O’Leary and Valdmanis (2020)). A Green Fund can sell its ability to put socially responsible proposals on the ballot as a feature of their fund and pay the cost out of the management fee. The question then is whether atomistic socially responsible investors are willing to put their money in the Green Fund.

As a benchmark we consider the case where the impact of engagement by a Green Fund is linear, that is, if a fraction $v$ of investors' wealth is placed with the fund, a fraction $v$ of firms will adopt the clean technology.

Suppose that the Green Fund controls a fraction $v$ of wealth at date 1 . That leads to $v N$ clean firms and $(1-v) N$ dirty firms. The resulting stock market equilibrium will be as in Section 3.4. Consider an investor's decision to divest from the Green Fund. Her current certainty 
equivalent is given by (5.1). If she divests, her certainty equivalent changes by $\frac{\partial C E}{\partial v} \Delta v$, where $\Delta v=-\frac{1}{r}$. So, as in the case of voting, the change in CE converges to zero as $r \rightarrow \infty$.

The remaining effects of divesting from the Green Fund are also exactly the same as with voting. The impact on the environment is given by (5.2) and the impact on other investors' wealth by (5.3). Thus, a socially responsible investor will choose to divest from the Green Fund if and only if $h<\delta$.

Our conclusion is that all the socially responsible investors will invest in the Green Fund if $h>\delta$ and none will invest if $h<\delta$. Hence, socially responsible mutual funds can help to achieve the social optimum.

The presence of intermediaries greatly relaxes the informational burden that the voice option imposes on investors. While it is hard to imagine that investors are sufficiently informed to vote on all ballot propositions, institutional investors have a fiduciary duty to exercise their voting rights. Thus, socially responsible investors can express their choices by picking the intermediary with the right "ideology", in the language of Bolton et al. (2020).

Note that a socially responsible fund can engage in ways other than just through voting. For example, Carleton et al. (1998) describe the behind-the-scenes engagement of TIAA-CREFF and Dimson et al. (2015) and Barko et al. (2018) show the effectiveness of behind-the-scenes engagement by socially responsible funds. One of the strategies that intermediaries use behind the scenes is to threaten to divest if management does not accede to their wishes. If credible, this strategy could induce management to compromise because it reduces the cost of doing so, but it is not useful to win more votes. The reason is that announcing that you will divest if the vote to become clean fails only makes it more attractive for other shareholders to vote dirty, since divestment lowers the price at which they can buy additional shares.

\subsection{Nonatomistic Investors}

The engagement result derived in Section 5.1 depends heavily on investors being well diversified, so that the impact of their decisions on the value of their own portfolio is infinitesimal. This is not true anymore if an investor is a significant stakeholder. In that case, a socially responsible investor will weigh the net social benefit of a vote for clean (multiplied by $\lambda$ ) against 
the reduced return on her portfolio due to the drop in profitability of the clean firm (multiplied by the investor's stake in that firm). Thus, significant investors (even if socially responsible) may vote dirty when this is socially inefficient.

In the value maximizing approach to corporate governance, large shareholders are often thought to be beneficial because they reduce the agency costs produced by the separation of ownership and control (Shleifer and Vishny (1997)). In contrast, in the socially responsible approach to corporate governance, large shareholders reduce the level of provision of public goods by firms and to that extent are undesirable.

Note that one downside of investors being well-diversified is that they have an incentive to persuade firms to take advantage of their monopoly power in the product market and raise consumer prices. This idea has received a great deal of attention recently (see Azar et al. (2018)). In order to guard against this we would advocate that only ESG proposals should be voted on, not those concerning prices and quantities. More important, we do not fear open votes to collude because these will attract the attention of the antitrust authorities.

\subsection{Takeovers}

A natural question to ask is whether takeovers affect engagement. As Hart and Zingales (2017) show (see also Elhauge (2005)), takeovers can undermine social action to turn companies clean, creating an "amoral drift.” Here we briefly sketch the argument.

Suppose that engagement leads a company to choose clean (provisionally). This means that it market value will be $V_{c}=F-\delta$. A (purely selfish) bidder could make an unconditional tender offer for the company at a price $p$ between $V_{c}$ and $V_{d}=F$, at the same time announcing that, if more than $50 \%$ of the shares are tendered, he plans to freeze-out nontendering shareholders at a price $p$ ' between $p$ and $V_{c}$. Even a socially responsible investor will tender. The reason is that given that she has a very small shareholding the chance that her tender decision will be pivotal is negligible. Furthermore, by not tendering she receives $p$ ' if the bid succeeds as opposed to $p$; while if the bid fails she owns shares worth $V_{c}$ rather than receiving $p$ (she could always buy back her shares). Thus tendering is a dominant strategy. Since everyone tenders the bid succeeds and the bidder makes a profit of $V_{d}-p$. This is true even if a majority of the investors are socially 
responsible and would have voted against the bid if given the chance. For further details, see Hart and Zingales (2017).

There is an asymmetry here. It is unlikely that a socially responsible bidder will buy a dirty company and turn it clean. The reason is that the bidder will have to pay at least $V_{d}$ to persuade shareholders to tender (at a lower price it would be profitable for someone, e.g., management to make a counteroffer), which means he loses $V_{d}-V_{c}$ on the transaction. There is an environmental gain of $h$, but this is weighted by $\lambda$. Thus only if $V_{d}-V_{c}=\delta<\lambda h$ will he proceed. In contrast, dispersed shareholders will vote for the company to become clean if $h>\delta$.

One important qualification to the above is that, as a result of a number of legal decisions in recent years and the existence of poison pills, it has become hard to take over a U.S. company if the majority is against the bid. These developments serve to mitigate the amoral drift, and make it less likely that takeovers will interfere with socially responsible engagement.

We can summarize our discussion of voice as follows. The conditions for voice to deliver a desirable social outcome are less stringent than the analogous conditions for exit. Consistent with our results, Dyck et al. (2019) find that divestment is not a driver of ESG performance change (at least as measured by ESG ratings), while shareholder engagement is.

\section{Robustness and Extensions}

\subsection{Visibility and Commitment}

So far we have assumed that individuals can commit to their strategy (be it divestment, or boycotting) and that this strategy is common knowledge. In practice, it is difficult for individuals

to communicate and commit to their strategy. Here technology and institutions might make a difference.

In our model firms are assumed to be aware that some investors (consumers) plan to divest (boycott). But how do they know this? One way is for investors or consumers to make announcements. In a pre-internet world, the authors of this paper could have announced that they would divest, but it would have been hard for anyone to know about it. In contrast, large institutions and companies could easily publicize their divestment and boycott decisions. Today, thanks to 
social media, this difference has become smaller, facilitating the announcement of divestments and boycotts.

Even today it is difficult to verify whether someone has carried through their announced strategy, given the variability of demand. ${ }^{21}$ Verification is important because there is a commitment issue. At date 1, some investors could announce that they will divest. This announcement might, if believed, be sufficient to push some companies to switch to clean. But, after having achieved their goal, the divestors will be tempted to sell the clean companies and buy the more profitable dirty ones, which trade at the same price. If this behavior is anticipated, divestment will become ineffective.

The same problem arises in the case of boycotts. Some consumers may announce that they will buy only clean products, causing some companies to install a clean technology. But once this is done what ensures that consumers do not renege on their promise and buy cheaper dirty products?

These commitment problems can exist even in the presence of intermediaries. Suppose that investors invest through a mutual fund, e.g., Fidelity. Fidelity might have a fund that plans to invest only in clean companies and another fund that plans to invest only in dirty companies. A socially responsible investor might put all her money in the Fidelity Green Fund. Seeing how much wealth has been invested in the Green Fund, some companies may elect to become clean. But once companies have made this decision what is to stop investors from switching their money from the Green Fund to the Dirty Fund? ${ }^{22}$

The commitment problem is stark in our setting because we study a one-shot game: firms make their production decisions at date 1 , then investors and consumers make their investment and consumption decisions, then the world ends. Reality is more complex and commitment may be easier to establish in a repeated setting.

\footnotetext{
21 See Ashenfelter et al. (2007).

22 One way in which a mutual fund can help increase the level of commitment is by offering only "clean" products, increasing the cost for investors to switch.
} 
Visibility can also help with commitment. Even today, if the authors of this paper announce that they will divest from oil companies, it would be hard for anyone to check. ${ }^{23}$ In contrast, the decision by the Harvard University endowment to achieve greenhouse gas neutrality by 2050 can easily be verified. ${ }^{24}$ In a similar fashion, on June 26, 2020 Unilever announced that it would not advertise on Facebook or Twitter for the rest of the year, citing hate speech and divisive content on the platforms. ${ }^{25}$ Unilever's action can easily be verified, and so Unilever is likely to stick to this commitment.

\subsection{Integer Issues}

We have assumed that firms can adjust continuously to the choices of investors and consumers, in the sense that $n_{c}$ is a continuous variable. If $n_{c}$ has to be an integer, this can affect the incentives to divest and boycott. Consider divestment first. Suppose we are at $\mu=0$ with $N>\frac{\delta}{\gamma \sigma^{2}}$. According to (4.8), if one investor divests, the number of clean firms becomes positive. But maybe $n_{c}$ equals 0.1 .

In our model this counts as a positive impact, possibly enough to motivate a socially responsible investor to divest. In reality, since a fraction of a firm is not feasible, the question is whether the new equilibrium would involve zero or one clean firm. Incorporating integer constraints is beyond the scope of this paper. We limit ourselves to noting that introducing these constraints is unlikely to strengthen the individual incentive to divest.

Next consider boycotting. The same considerations apply as with divesting: one person's boycott might lead $n_{c}$ to increase by 0.1 . However, in this case there is a natural interpretation. We can imagine that a firm can choose a convex combination of clean and dirty, that is it can at a cost $\alpha \delta$ produce $\alpha$ units of clean product and 1- $\alpha$ units of dirty product, where $\alpha \in[0,1]$. Then, if one consumer boycotts a firm can switch to a small amount of clean production to satisfy that consumer.

\footnotetext{
${ }^{23}$ However, someone who makes a personal decision to divest or boycott may incur a personal cost if they deviate from this decision, which can help to sustain commitment. See, e.g., Ederer and Stremitzer (2017). Note that commitment is not an issue in the literature that assumes that people divest or boycott for moral reasons.

${ }^{24}$ See https://www.thecrimson.com/article/2020/4/22/endowment-ghg-neutral-2050/

${ }^{25}$ See https://www.wsj.com/articles/unilever-to-halt-u-s-ads-on-facebook-and-twitter-for-rest-of-2020-11593187230.
} 


\subsection{Labor Boycott}

Our simple model does not have any labor costs, let alone the possibility of workers boycotting a firm. Yet, in a competitive labor market the effect of a labor boycott is very similar to the effect of the consumer boycott we analyzed in Section 4.2. Purely selfish workers work for any firm, while socially responsible workers boycott dirty firms. The resulting equilibrium would be similar to that in Section 4.2, with workers in dirty firms being paid more than workers in clean firms and the equilibrium level of clean firms depending on the slope of the labor demand curve. Indeed, Nyborg and Zhang (2013) provide evidence that workers in socially responsible firms are paid less.

The situation is different if a firm has some market power. Consider, for instance, a case where there is one monopsonist and many workers. The monopsonist has the choice to stay dirty and be able to hire only from a smaller pool of workers or pay the cost $\delta$ and be able to hire all workers. As we discuss in the Appendix, when the market is not competitive, if the pool of boycotters is large enough, not only will boycotters be able to turn the firm clean, but they will be able to do so without bearing any cost.

\subsection{Rational Expectation Equilibrium}

We have assumed that the harm at date 1 is unanticipated at date 0 . Relaxing this assumption does not change the analysis very much. If all investors and consumers are purely selfish, it does not change it at all since the date 1 market value of firms will be independent of $h$, and so the incentives of entrepreneurs to set up firms at date 0 will be unaffected. On the other hand, if divestment or boycotting by socially responsible investors or consumers is anticipated to occur at date 1 , then this reduces the date 1 and date 0 market value of firms, and so the equilibrium number of firms will be lower. The same is true if it is anticipated that successful engagement will cause firms to choose the clean technology since this reduces future profitability. ${ }^{26}$

\subsection{Social Entrepreneurs}

${ }^{26}$ Given this, founders of firms at date 0 may try to make engagement more difficult at date 1 through provisions in the corporate charter, for example, by putting in super-majority provisions or a dual-class voting structure. 
We have assumed that the entrepreneurs at date 0 who set up companies are interested only in money. But suppose that some of them are socially responsible. If they anticipate the harm at date 1 might they try to influence their firms to act in a socially responsible way? In our setting this is difficult to achieve. The reason is that we have assumed free entry, that is an infinite supply of entrepreneurs. Even if some are socially responsible many are likely not to be. As a result, in the free entry equilibrium the market value of a firm that does not encourage social responsibility will be $F$ and the market value of a firm that does encourage social responsibility will be below $F$. Since we have assumed that entrepreneurs have zero wealth they will not be able to finance the latter. In effect competition drives out good behavior.

Note that the situation is different at date 1 . At this point the entry cost $F$ is sunk and so firms earn rents. Therefore, firms have the ability to choose clean without being driven out of the market.

\section{$\underline{\text { 7. Discussion }}$}

\subsection{Awareness and Social Pressure Campaigns}

The biggest limitation of our analysis is that we take social preferences as given. As a result, we miss an important benefit of exit campaigns: their effect on social preferences. Black Americans’ boycott of municipal transportation in Montgomery (Alabama) in 1955 informed all Americans about the cost of segregation, changing many people's preferences. The fur-free campaign launched by the Humane Society is not just the announcement of a boycott, but an attempt to shame fur users, i.e., to lead purely selfish individuals to behave as if they were socially responsible consumers. $^{27}$

When it comes to informing and changing people's preferences the exit strategy is superior to the voice one. A successful information campaign can keep the relevant piece of news in the media for an extended period of time. A corporate vote is not so newsworthy to begin with. The media feel compelled to cover it at most twice, when the vote is announced and when the votes are counted. By contrast, an exit campaign is newsworthy every time a famous person/institution joins the exiters. Thus, exit is more effective at communicating the news.

\footnotetext{
27 https://www.humanesociety.org/all-our-fights/going-fur-free.
} 
Exit is also more effective at pressuring people into behaving socially, even if their $\lambda$ is equal to zero. It is not only peer pressure that operates, but also the pressure to join a growing and potentially successful movement (Thaler and Sunstein (2008)). Both these forces help a highly motivated minority to achieve some successes it would never be able to achieve through a voice strategy. Consistent with this idea, corporate boycotts succeed mostly by affecting a target's reputation in the media, not the demand for their product (King (2011)).

For these reasons, a highly-motivated minority might find exit a more successful strategy than voice. Yet, there is no guarantee that its ability to succeed is linked to the social desirability of its goal. Thus, extending the model to incorporate information and social pressure is unlikely to change the fundamental result that voice is more aligned to social incentives than exit.

\subsection{Best Strategy Contingent on Size}

If a majority of investors is socially responsible, voice will deliver the socially desirable outcome. Even when socially responsible investors are not a majority, as long as they can concentrate their holdings in a subset of firms in which they represent a majority (without affecting much the diversification of their portfolio), they can have an impact that is proportional to their size. Thus, they can do better that an exit strategy, which will have an impact less than proportional to the mass of socially responsible consumers/investors.

Problems start to arise when socially responsible consumers/investors represent such a

small minority that they cannot reach a majority of the votes in any single firm without significantly reducing the diversification of their portfolio. In such situations, the exit strategy may more effective.

\subsection{Legal Restrictions}

Boycotting and divesting are hard to restrict by legal means. Not surprisingly, they have been the strategy of choice for insurrectional movements, from the American colonies' boycott of British tea in 1773 to the Indian boycott of British textiles in 1921. In contrast, voice can be easily restricted so much to become ineffective.

In the United States shareholder proposals are only precatory (i.e., not binding). In addition, management can easily prevent a proposal from appearing on the ballot by invoking the "ordinary business operations exception”, which allows management to exclude proposals that 
relate to its ordinary business operations. For example, in its attempts to reduce sales of assault weapons Trinity Church submitted a shareholder proposal for inclusion in Walmart's 2014 proxy materials, asking the Walmart board to oversee the sale of "products that especially endanger public safety and well-being, risk impairing the company's reputation, or offend the family and community values integral to the company's brand." The SEC (and later the U.S. Court of Appeals) upheld the Walmart management's decision to use the ordinary business exception to exclude this proposal from the ballot. Thus, shareholder voice could not be heard on this important issue because of legal constraints.

In case this was not enough, the US Department of Labor has recently released a new proposal that requires private pension fund managers to focus only on maximizing financial returns

for their beneficiaries, ignoring any ESG factor. ${ }^{28}$ While possibly motivated by the desire to avoid the expropriation of pension investors by asset managers, this might have the effect of preventing pension investors from expressing their preferences through voice.

Thus, another major limitation of the voice strategy is that it can easily be restricted.

\section{Conclusions}

This paper is an attempt to analyze the welfare implications of two traditional strategies aimed at shaping corporate outcomes: exit and voice. To make the problem tractable we have made a number of simplifying assumptions: identical firms with zero marginal cost up to a capacity constraint, a linear demand curve, constant absolute risk aversion, normal distribution, etc. We have also studied the three principal socially responsible strategies, divestment, boycotting and engagement, separately, without considering how they might interact with each other. Subject to these limitations, we find that in a competitive world exit is less effective than voice in pushing firms to act in a socially responsible manner. Furthermore, we find that individual incentives to join an exit strategy are not necessarily aligned with the social incentive, while they are when investors are allowed to express their voice.

We have derived these results under the best possible scenario for the exit strategies: investors and consumers who can announce their strategies to the world and commit to them. If we relax these assumptions exit becomes even less effective.

${ }^{28}$ https://www.dol.gov/newsroom/releases/ebsa/ebsa20200623. 
One question raised by our paper is why social engagement is relatively rare in spite of all its desirable properties. In some cases, engagement is infeasible because somebody owns a majority of the votes, such as Mark Zuckerberg with Facebook, or the company is privately held, such as Koch Industries. We think that an important additional factor resides in the current U.S. proxy system, which tends to limit shareholders' ability to influence corporate policy. The restrictions reflect a fear that individual shareholders are activists in the sense that they put a lot of weight on a single issue (e.g., their utility is $-N h$ ). If instead individuals are socially responsible (in the way we define), this fear is unfounded. Individual shareholders have the incentive to vote on issues in a socially optimal way and their engagement can lead to more efficient outcomes. 


\section{References}

Acquatella, Angie. 2020. “Optimal Reimbursement Contracts for Physician Administered Treatments.” Harvard, mimeo.

Aghion, Philippe, Roland Bénabou, Ralf Martin and Alexandra Roulet. 2020. "Environmental Preferences and Technological Choices: Is Market Competition Clean or Dirty?” CEP Discussion Paper No 1684 March 2020

Andersson, Mats, Patrick Bolton \& Frédéric Samama (2016). “Hedging Climate Risk”. Financial Analysts Journal, 72:3, 13-32,

Andreoni, James. 1989. "Giving with Impure Altruism: Applications to Charity and Ricardian Equivalence.” Journal of Political Economy 97 (6): 1447-1458.

Andreoni, James, and John Miller. 2002. "Giving according to GARP: An experimental test of the consistency of preferences for altruism.” Econometrica, 70 (2), 737-753.

Ashenfelter Orley C., Ciccarella Stephen, and Shatz Howard J. 2007. "French Wine and the U.S. Boycott of 2003: Does Politics Really Affect Commerce?” NBER Working Paper \# 13258

Azar, José, Martin C. Schmalz, and Isabel Tecu. 2018. “Anticompetitive effects of common ownership.” The Journal of Finance 73(4): 1513-1565.

Bagnoli, Mark, and Watts Susan G. 2003. "Selling to Socially Responsible Consumers: Competition and The Private Provision of Public Goods.” Journal of Economics \& Management Strategy 12 (3): 41945. https://doi.org/10.1111/j.1430-9134.2003.00419.x.

Barber, Brad, Adair Morse, and Ayako Yasuda. 2020. “Impact Investing.” Journal of Financial Economics, forthcoming.

Barko, Tamas, Cremers, K. J. Martijn, and Renneboog, Luc. 2018. "Shareholder Engagement on Environmental, Social, and Governance Performance”. CentER Discussion Paper Series No. 2017040.

Baron, David P. 2001. “Private Politics, Corporate Social Responsibility, and Integrated Strategy.” Journal of Economics and Management Strategy, 10(1): 7-45.

Baron, David P. 2007. “Corporate Social Responsibility and Social Entrepreneurship.” Journal of Economics \& Management Strategy 16 (3): 683-717. https://doi.org/10.1111/j.15309134.2007.00154.x.

Barrios, John, Efraim Benmelech, Yael V. Hochberg, Paola Sapienza, and Luigi Zingales. 2020. “Civic Capital and Social Distancing during the Covid-19 Pandemic.” NBER WP.

Bauer, Rob, Tobias Ruof, and Paul Smeets. 2020. "Get real! individuals prefer more sustainable investments.” Working Paper. 
Bebchuk, Lucian A. and Tallarita, Roberto. 2020. “The Illusory Promise of Stakeholder Governance.” Cornell Law Review, December.

Bénabou, Roland, and Jean Tirole. 2010. “Individual and Corporate Social Responsibility.” Economica 77 (305): 1-19. https://doi.org/10.1111/j.1468-0335.2009.00843.x.

Besley, Timothy, and Maitreesh Ghatak. 2007. "Retailing Public Goods: The Economics of Corporate Social Responsibility.” Journal of Public Economics 91 (9): 1645-63. https://doi.org/10.1016/j.jpubeco.2007.07.006.

Besley, Timothy, and Maitreesh Ghatak. 2018. "Prosocial Motivation and Incentive.” Annual Review of Economics 10:411-38.

Bolton, Patrick, Li, Tao, Ravina, Enrichetta, and Rosenthal, Howard. 2020. “Investor Ideology.” Journal of Financial Economics, August: 320-352.

Bonnefon, Jean-Francois, Landier, Augustin, Sastry, Parinitha and Thesmar, David. 2019. "Do Investors Care About Corporate Externalities? Experimental Evidence.” HEC Paris Research Paper No. FIN2019-1350.

Brodback, Daniel, Nadja Guenster, and David Mezger. 2019. "Altruism and Egoism in Investment Decisions.” Review of Financial Economics 37 (1): 118-48. https://doi.org/10.1002/rfe.1053.

Brown, Ira V. 1988. “Pennsylvania’s Antislavery Pioneers, 1688-1776.” Pennsylvania History: A Journal of Mid-Atlantic Studies 55(2): 59-77.

Carleton, Willard T., Nelson, James M., \& Michael S. Weisbach. 1998. "The influence of institutions on corporate governance through private negotiations: Evidence from TIAA-CREF.” Journal of Finance, 53: $1335-1362$.

CBINSIGHTS. 2020. State of Fintech: Investment \& Sector Trends to Watch, https://www.cbinsights.com/research/report/fintech-trends-q4-2019/

Charness, Gary, and Matthew Rabin. 2002. “Understanding Social Preferences with Simple Tests.” The Quarterly Journal of Economics 117 (3): 817-69. https://doi.org/10.1162/003355302760193904.

Chowdhry, Bhagwan, Shaun William Davies, and Brian Waters. 2019. "Investing for Impact.” The Review of Financial Studies 32 (3): 864-904. https://doi.org/10.1093/rfs/hhy068.

Christensen, Hans B., Luzi Hail, and Christian Leuz. 2019. “Adoption of CSR and Sustainability Reporting Standards: Economic Analysis and Review.” NBER Working Paper \# 26169. URL: http://www.nber.org/papers/w26169

Davies, Shaun William, and Edward Dickersin Van Wesep. 2018. “The Unintended Consequences of Divestment.” Journal of Financial Economics 128 (3): 558-75. https://doi.org/10.1016/j.jfineco.2018.03.007.

Dimson, Elroy, Oğuzhan Karakaş, and Xi Li. 2015. “Active Ownership.” Review of Financial Studies 28 (12): 3225-68. https://doi.org/10.1093/rfs/hhv044. 
Dyck, Alexander, Karl V. Lins, Lukas Roth, and Hannes F. Wagner. 2019. “Do Institutional Investors Drive Corporate Social Responsibility? International Evidence.” Journal of Financial Economics 131 (3): 693-714. https://doi.org/10.1016/j.jfineco.2018.08.013.

Ederer, Florian, and Alezander Stremitzer. 2017. "Promises and Expectations.” Games and Economic Behavior, 106(C): 161-178.

Edmans, Alex. 2020. Grow the Pie: How Great Companies Deliver Both Purpose and Profit. Cambridge University Press.

Elhauge, Einer. 2005. "Sacrificing Corporate Profits in the Public Interest.” New York University Law Review. 80(3): 733-869.

Frydlinger, David, and Oliver D. Hart. 2019. “Overcoming Contractual Incompleteness: The Role of Guiding Principles.” NBER Working Paper \# 26245. https://doi.org/10.3386/w26245.

Gollier Christian, and Sébastien Pouget. 2014. "The "Washing Machine”: Investment Strategies and Corporate Behavior with Socially Responsible Investors”, TSE Working Paper, n.14-457, January 2014.

Graff Zivin, Joshua, and Arthur Small. 2005. “A Modigliani-Miller Theory of Altruistic Corporate Social Responsibility.” Topics in Economic Analysis \& Policy 5 (1): 1-19. https://doi.org/10.2202/1538$\underline{0653.1369 .}$.

Hart, Oliver, and Luigi Zingales. 2017. "Companies Should Maximize Shareholder Welfare Not Market Value.” Journal of Law, Finance, and Accounting 2 (2): 247-75. https://doi.org/10.1561/108.00000022.

Hartzmark, Samuel M., and Abigail B. Sussman. 2019. "Do Investors Value Sustainability? A Natural Experiment Examining Ranking and Fund Flows.” The Journal of Finance 74 (6): 2789-2837. https://doi.org/10.1111/jofi.12841.

Heinkel, Robert, Alan Kraus, and Josef Zechner. 2001. "The Effect of Green Investment on Corporate Behavior.” The Journal of Financial and Quantitative Analysis 36 (4): 431-449. https://doi.org/10.2307/2676219.

Hendel, Igal, Saul Lach, and Yossi Spiegel. 2017, “Consumers’ Activism: The Cottage Cheese Boycott.” RAND Journal of Economics, Vol. 48, No. 4, Winter 2017 pp. 972-1003

Hirschman, Albert O. 1970. Exit, Voice, and Loyalty: Responses to Decline in Firms, Organizations, and States. Cambridge: Harvard University Press.

Homanen, Mikael. 2018. “Depositors Disciplining Banks: The Impact of Scandals”. Chicago Booth Research Paper No. 28.

Hong, Harrison, and Marcin Kacperczyk. 2009. "The Price of Sin The Effects of Social Norms on Markets.” Journal of Financial Economics, 93: 15-36. 
King, Brayden G. 2011. The Tactical Disruptiveness of Social Movements Sources of Market and Mediated Disruption in Corporate Boycotts,” Social Problems, Vol. 58, No. 4 (November 2011), pp. 491-517

Kitzmueller, Markus, and Jay Shimshack. 2012. "Economic Perspectives on Corporate Social Responsibility.” Journal of Economic Literature 50 (1): 51-84. https://doi.org/10.1257/jel.50.1.51.

Laidlaw, James. 1995. Riches and Renunciation. Religion, Economy, and Society among the Jains, Clarendon Press, Oxford.

Magill, Michael, Martine Quinzii, and Jean-Charles. Rochet. 2015. “A Theory of the Stakeholder Corporation.” Econometrica 83(5): 1685-1725.

Mas-Colell, Andreu, Michael D. Whinston, and Jerry R. Green. 1995. Microeconomic Theory, Oxford University Press.

Mayer, Colin. 2018. Prosperity: Better Business Makes the Greater Good. Oxford University Press.

Morgan, John, and Justin Tumlinson. 2019. “Corporate Provision of Public Goods.” Management Science 65 (10): 4489-4504. https://doi.org/10.1287/mnsc.2018.3137.

Nyborg, Karine, and Tao Zhang. 2013. “Is corporate social responsibility associated with lower wages?' Environmental and Resource Economics 55(1): 107-117

Oehmke, Martin, and Marcus M. Opp. 2019. “A Theory of Socially Responsible Investment.” SSRN Electronic Journal. https://doi.org/10.2139/ssrn.3467644.

O’Leary and Valdmanis. 2020. Accountable: The Rise of Citizen Capitalism, Harper Business.

Olson, M. 1965. The logic of collective action: Public goods and the theory of group, Harvard University Press, Cambridge, Massachusetts.

Pastor, Lubos, Robert F Stambaugh, and Lucian A. Taylor. 2020. "Sustainable investing in equilibrium.” Journal of Financial Economics, forthcoming.

Pedersen, Lasse Heje, Shaun Fitzgibbons, and Lukasz Pomorski. 2019. "Responsible Investing: The ESGEfficient Frontier.” SSRN Electronic Journal. https://doi.org/10.2139/ssrn.3466417.

Pruitt, Stephen W., and Monroe Friedman. 1986. "Determining the Effectiveness of Consumer Boycotts: A Stock Price Analysis of Their Impact on Corporate Targets.” Journal of Consumer Policy 9 375387.

Riedl, Arno, and Paul Smeets. 2017. "Why Do Investors Hold Socially Responsible Mutual Funds?” The Journal of Finance 72 (6): 2505-50. https://doi.org/10.1111/jofi.12547.

Schoenmaker, Dirk and Willem Schramade. 2019. Principles of Sustainable Finance, Oxford University Press. 
Shleifer, Andrei, and Robert W Vishny. 1997. “A Survey of Corporate Governance.” Journal of Finance 52 (2): 737-783.

Stout, Lynn. 2012. The Shareholder Value Myth. San Francisco: Berrett-Koehler Publishers, Inc.

Sugden, Robert. (1982). “On the Economics of Philanthropy.” The Economic Journal 92(366): 341-350.

Sugden, Robert, 1984. "Reciprocity: The Supply of Public Goods through Voluntary Contributions.” Economic Journal, 94(376): 772-787.

Thaler, Richard H. and Cass R. Sunstein. 2008. Nudge: Improving Decisions About Health, Wealth, and Happiness, Penguin Books

Teoh, Siew Hong, Ivo Welch, and C. Paul Wazzan. 1999. "The effect of socially activist investment policies on the financial markets: Evidence from the South African Boycott.” Journal of Business, vol. 72, no. 1: 35-89. 


\section{Appendix}

\section{A.1 The Monopoly Case}

A natural question to ask is how much our results change if firms have some monopoly power, either because they are large or because they supply a distinctive product. While we cannot do justice to this topic here, we can provide some preliminary analysis. To proceed we ignore investors and focus on consumers.

Suppose that there is a single firm at date 1 that has zero marginal cost. (It incurred a fixed cost $F$ at date 0 but this is now sunk.) In order to capture the idea that this firm has monopoly power, we drop the capacity constraint. The firm faces $n$ consumers. The firm can become clean at fixed cost $\delta$. If it does not become clean it creates environmental harm equal to $h Q$, where $Q$ is the firm's total output. This harm is spread equally over the consumers. Each consumer has the utility function given in (3.3). A fraction $\pi$ of these consumers are socially responsible with parameter $\lambda$; the rest are purely selfish.

Start with the case where there is no boycott and the firm is run by a profit-maximizing manager. Each consumer's demand curve is given by

$$
p=\rho-\tau q,
$$

where $q$ is individual consumption. In equilibrium, $q=\frac{Q}{n}$, and so the firm's demand curve is

$$
p=\rho-\tau \frac{Q}{n} .
$$

The firm maximizes revenue given by

$$
p Q=\rho Q-\tau \frac{Q^{2}}{n} .
$$

The first order condition is

$$
Q=\frac{\rho n}{2 \tau} \quad \text { and } p=\frac{\rho}{2} .
$$

The firm's profit and environmental harm are, respectively,

$$
\Pi=p Q=\frac{\rho^{2} n}{4 \tau},
$$




$$
H=h Q=\frac{h \rho n}{2 \tau} .
$$

Obviously, the firm has no incentive to become clean since this reduces its profits by $\delta$.

Consider now what happens if all socially responsible investors announce that they will boycott the firm's product unless it is clean (we suppose that consumers can stick to this commitment). The firm has a choice. It can remain dirty and sell only to purely selfish consumers or it can become clean and sell to everybody. In the first case, its market is a fraction $(1-\pi)$ of what it was before. Its demand curve is

$$
p=\rho-\frac{\tau Q}{(1-\pi) n},
$$

and it maximizes its revenues given by

$$
p Q=\rho Q-\frac{\tau Q^{2}}{(1-\pi) n} .
$$

The optimum is

$$
Q=\frac{\rho(1-\pi) n}{2 \tau} \quad \text { and } p=\frac{\rho}{2},
$$

and the firm's profit and environmental harm are

$$
\begin{gathered}
\Pi=\frac{\rho^{2}(1-\pi) n}{4 \tau}, \\
H=\frac{h \rho(1-\pi) n}{2 \tau} .
\end{gathered}
$$

The alternative is for the firm to incur the fixed cost $\delta$ and sell to everybody. In this case, (A.2)-(A.4) apply and the firm's profit is

$$
\Pi^{\prime}=\frac{\rho^{2} n}{4 \tau}-\delta,
$$

which we assume to be nonnegative.

Comparing (A.10) and (A.12), we see that the firm will choose to become clean if and only if

$$
\pi>\frac{4 \delta \tau}{\rho^{2} n} .
$$


Obviously, if (A.13) does not hold, there are not enough socially responsible consumers to persuade the firm to choose clean. In contrast, if (A.13) does hold, a boycott can induce the firm to choose clean. Moreover, it is an equilibrum for all socially responsible consumers to boycott. The reason is that, since the firm chooses clean, it is costless to boycott: there is no cheaper dirty product available that the consumer is forgoing.

Although a boycott can occur if (A.13) holds, we now consider whether it can also be an equilibrium for nobody to boycott. If one consumer boycotts when nobody else does the amount of pollution is reduced by $h q$, where $q$ is the individual's demand, given by (A.1) with $p=\frac{\rho}{2} .29$ That is, pollution is reduced by

$$
\frac{h \rho}{2 \tau} .
$$

Social welfare, excluding the consumer's own utility, increases by

$$
\frac{h \rho}{2 \tau}-\frac{\rho}{2} q=\frac{h \rho}{2 \tau}-\frac{\rho^{2}}{4 \tau},
$$

where the second term reflects the decrease in the firm's profit from not selling to this consumer.

By not purchasing, the consumer loses all her consumer surplus, given by

$$
\rho q-\frac{1}{2} \tau q^{2}-p q=\frac{\rho^{2}}{8 \tau}
$$

In deciding whether to boycott the consumer therefore compares (A.16) with (A.15), where the latter is weighted by $\lambda$. The conclusion is that the consumer will not boycott if

$$
\frac{\rho^{2}}{8 \tau} \geq \lambda\left(\frac{h \rho}{2 \tau}-\frac{\rho^{2}}{4 \tau}\right)
$$

which can be simplified to

$$
\rho \geq 4 h \frac{\lambda}{1+2 \lambda}
$$

\footnotetext{
${ }^{29}$ Note that this effect is not present in the competitive model of Section 3, since the number of firms $\mathrm{N}$ is given and, whether a firm is clean or dirty, it produces the same quantity of product with the same amount of pollution. Whether in practice a reduction in demand can curb a firm's externality even when it is not sufficient to induce a change in technology depends a great deal on the nature of the externality. Reducing demand for furs reduces the number of animals killed in a proportional way, but reducing the demand for Facebook ads does not change proportionally the amount of hate speech on Facebook.
} 
It is easy to see that this condition will hold as long as a benevolent planner who is constrained to decide whether a dirty firm should operate at all or close down would choose to let the firm operate. The total surplus from a dirty firm that produces $Q$ units, divided equally among consumers, is

$$
n\left(\frac{\rho}{2} \frac{Q}{n}-\frac{1}{2} \tau\left(\frac{Q}{n}\right)^{2}\right)-h Q=\frac{\rho}{2} Q-\frac{1}{2} \frac{\tau Q^{2}}{n}-h Q .
$$

For this to be positive we must have

$$
\rho>2 h,
$$

which implies (A.18).

When all socially responsible consumers boycotting and none boycotting are both equilibria, one can ask which equilibrium is more plausible. A full analysis is beyond the scope of this paper, but one consideration is worth noting. The consumers are better off in the boycott equilibrium. The reason is that, given that the boycott succeeds, the firm produces the same amount as without the boycott at the same price, but absorbs the cost $\delta$. In return, the consumers enjoy a cleaner environment: harm falls by $h Q$. Thus, the boycott redistributes surplus from the monopolist to consumers regardless of the size of $h$.

Related to this observation, there is no simple relationship between the market outcome and the social optimum. Similar to Section 3.4, consider a social planner who operates in a world where all consumers are purely selfish and can choose the technology but cannot control the firm's monopoly power. The equilibrium level of the firm is the same whether the firm is clean or dirty; it is given by $Q=\frac{\rho n}{2 \tau}$ (see (A.4)). Thus, the only difference between the two situations is that choosing clean induces an extra cost $\delta$, but reduces environmental harm by $\frac{h \rho n}{2 \tau}$. It follows that the planner will choose clean if and only if

$$
\delta<\frac{h \rho n}{2 \tau} .
$$

Comparing (A.13) and (A.21), we see that boycotts can occur when they are not socially optimal and not occur when they are.

As previously, commitment is an issue. Here, a further question arises. If consumers can commit to a boycott, why can't they commit not to buy the product at any price above average cost 
(here, zero) $?^{30}$ One argument for why a commitment to boycott might be easier to sustain is that reneging on a boycott may be visible whereas paying more than you said you would may not be. Also the reputational loss from reneging on a boycott may be bigger than that from breaching a price commitment.

${ }^{30}$ Hendel et al. (2017) provide an example of a boycott to reduce prices in excess of marginal cost. 